Subscriber access provided by Universidad de Alicante

\title{
Article
}

\section{Spectroelectrochemical Study of CO2 Reduction on TiO2 Electrodes in Acetonitrile}

Néstor E. Mendieta-Reyes, William Cheuquepán, Antonio Rodes, and Roberto Gómez

ACS Catal., Just Accepted Manuscript • DOI: 10.1021/acscatal.9b02932 • Publication Date (Web): 06 Nov 2019

Downloaded from pubs.acs.org on November 12, 2019

\section{Just Accepted}

"Just Accepted" manuscripts have been peer-reviewed and accepted for publication. They are posted online prior to technical editing, formatting for publication and author proofing. The American Chemical Society provides "Just Accepted" as a service to the research community to expedite the dissemination of scientific material as soon as possible after acceptance. "Just Accepted" manuscripts appear in full in PDF format accompanied by an HTML abstract. "Just Accepted" manuscripts have been fully peer reviewed, but should not be considered the official version of record. They are citable by the Digital Object Identifier (DOIB). "Just Accepted" is an optional service offered to authors. Therefore, the "Just Accepted" Web site may not include all articles that will be published in the journal. After a manuscript is technically edited and formatted, it will be removed from the "Just Accepted" Web site and published as an ASAP article. Note that technical editing may introduce minor changes to the manuscript text and/or graphics which could affect content, and all legal disclaimers and ethical guidelines that apply to the journal pertain. ACS cannot be held responsible for errors or consequences arising from the use of information contained in these "Just Accepted" manuscripts. 


\title{
Spectroelectrochemical Study of $\mathrm{CO}_{2}$ Reduction
}

\section{on $\mathrm{TiO}_{2}$ Electrodes in Acetonitrile.}

\author{
Néstor E. Mendieta-Reyes ${ }^{\mathrm{ab}}$, William Cheuquepán ${ }^{\mathrm{a} \dagger}$, Antonio Rodes ${ }^{\mathrm{a}}$, Roberto Gómez ${ }^{\mathrm{a}}$ \\ a Institut Universitari d'Electroquímica i Departament de Química Física, Universitat d'Alacant, \\ Apartat 99, E-03080 Alicante, Spain. \\ ${ }^{b}$ Departamento de Química, Facultad de Ciencias, Universidad Nacional de Colombia, Cra 30 \\ \# 45-03, Edificio 451, 11001 Bogotá, Colombia.
}

*Corresponding author: E-mail: Roberto.Gomez@ua.es; tel: +34 965903748 


\begin{abstract}
One of the main current goals of humanity is the $\mathrm{CO}_{2}$ conversion into compounds with energetic value for facilitating both a diminution of the $\mathrm{CO}_{2}$ atmospheric levels and the development of energy storage strategies. In many studies, $\mathrm{TiO}_{2}$ has been successfully used as a photocatalyst for $\mathrm{CO}_{2}$ reduction, but there is still a lack of understanding of its catalytic behavior. In this context, $\mathrm{CO}_{2}$ reduction has been studied on nanoporous $\mathrm{TiO}_{2}$ electrodes in acetonitrile media by means of (spectro)electrochemical methods (ATR-IR and UV-vis). Importantly, the onset of the cathodic Faradaic processes related with $\mathrm{CO}_{2}$ reduction on $\mathrm{TiO}_{2}$ electrodes is located at $-0.81 \mathrm{~V}$ vs. SHE, which is less negative than that observed for metal electrodes under similar conditions. $\mathrm{UV}$-vis spectroelectrochemical results indicate that the electrocatalytic behavior of $\mathrm{TiO}_{2}$ is related to the generation of oxygen vacancies and $\mathrm{Ti}^{3+}$ sites at its surface, promoted by electrolytes with non-intercalating cations in agreement with recent results on $\mathrm{WO}_{3}$ electrodes. ATR-IR spectroelectrochemical measurements allow for a monitoring of the $\mathrm{TiO}_{2} /$ solution interfacial state as reduction proceeds. Specifically, IR bands for carbon monoxide and carbonyl groups related with carbonate and oxalate are observed. Additionally, a chromatographic analysis shows $\mathrm{CO}$ and oxalate as main products. With controlled water addition $(0.5 \mathrm{M})$, methanol and $\mathrm{CO}$ were found to be the main products. Based on these results, a mechanism for $\mathrm{CO}_{2}$ reduction on $\mathrm{TiO}_{2}$ electrodes is presented in which the regeneration of the $\mathrm{TiO}_{2}$ surface by oxide electrodissolution/deposition is a critical step.
\end{abstract}

KEYWORDS: $\mathrm{CO}_{2}$ reduction; $\mathrm{TiO}_{2}$ electrodes; ATR-IR spectroelectrochemistry; UV-vis spectroelectrochemistry; electrochromism; electrocatalysis 


\section{TABLE OF CONTENTS GRAPHIC}

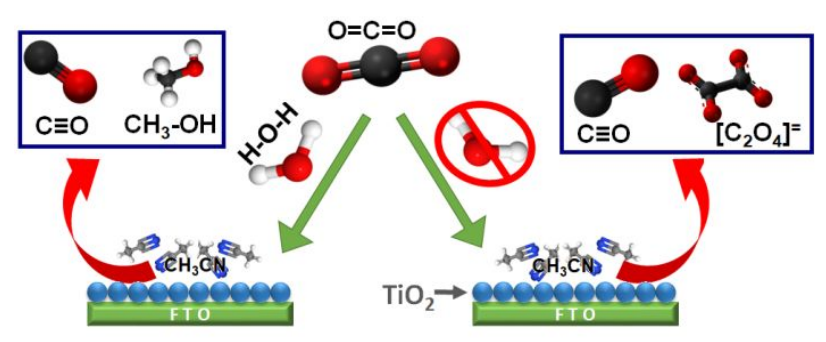

\section{INTRODUCTION}

The trend to increase the atmospheric carbon dioxide levels from $280 \mathrm{ppmv}$ in preindustrial times to more than 400 ppmv today (a 43\% increase, with half of it occurring since 1965), mainly because of the combustion of fossil fuels, is raising serious concerns about the ensuing rise in Earth's global temperature. This has motivated many research groups in the world to search for feasible ways to reduce $\mathrm{CO}_{2}$ emissions and/or to reutilize it by conversion into other chemical compounds with energy value, leading to alternative energy storage strategies. ${ }^{1,2}$ Extensive reviews on catalytic reactions with the use of $\mathrm{CO}_{2}$ as a feedstock source and on different approaches for $\mathrm{CO}_{2}$ reduction have been published. ${ }^{3,4}$ Photocatalytic and homogeneous and heterogeneous electrocatalytic reduction processes seem to be effective ways for processing carbon dioxide. ${ }^{5,6}$ Many different products have been obtained depending on the specific reaction pathway and, obviously, on the number of transferred electrons, which determines the final oxidation state of the carbon atom. ${ }^{7,8}$ Factors such as the solvent (aqueous vs nonaqueous, protic vs aprotic, ionic liquids, supercritical $\mathrm{CO}_{2}$ ), electrolyte, $\mathrm{pH}$, temperature, concentration of $\mathrm{CO}_{2}$, the choice of electrode material, its surface structure, electrode potential, among others can affect the reduction pathway. ${ }^{9-12}$ 
The carbon dioxide molecule is a very stable, linear molecule, with a closed-shell electronic configuration. The $\mathrm{CO}_{2}$ reduction is an endergonic reaction, because of the low electron affinity of $\mathrm{CO}_{2}(0.6 \mathrm{eV})$, related with the high energy level of its LUMO, and the increased repulsion between the free electron pairs in the oxygen atoms and the newly added electron in the carbon atom. Thus, the generation and stabilization of the $\mathrm{CO}_{2}^{-}$anion radical is key to achieving efficient $\mathrm{CO}_{2}$ reduction. The $\mathrm{CO}_{2}$ molecule can be activated over a solid-state catalyst, the role of which is to adsorb $\mathrm{CO}_{2}$ molecules, facilitating electron transfer from the solid. ${ }^{13}$ In this respect, the formation of $\mathrm{CO}_{2}^{\delta} \cdot-$ over different metal oxides has been extensively reported. ${ }^{14-17}$

In aqueous solution, different factors such as low solubility of $\mathrm{CO}_{2}$ under ambient conditions, the existence of acid-base equilibria and hydrogen evolution occurring as a competitive process induce a loss of efficiency and selectivity. In this sense, non-aqueous aprotic solvents such as acetonitrile (ACN) have been used for studying $\mathrm{CO}_{2}$ reduction. These solvents provide a wider electrochemical window to carry out reductions (down to $-2.5 \mathrm{~V}$ vs $\mathrm{Ag} / \mathrm{Ag}^{+}$ electrodes) due to the difficulty of breaking $\mathrm{C}-\mathrm{H}$ bonds in $\mathrm{ACN}$, in contrast with $\mathrm{O}-\mathrm{H}$ bonds in water. Additionally, the solubility of $\mathrm{CO}_{2}$ in $\mathrm{ACN}$ at 1 atm and room temperature is $280 \mathrm{mM}$, which is approximately 8 times that in water. ${ }^{18,19}$ The mechanism of $\mathrm{CO}_{2}$ reduction on metal electrodes in nonaqueous solvents with low proton availability has been reported by Amatore and Saveant ${ }^{20}$ and later by Gennaro et al. ${ }^{21}$ The $\mathrm{CO}_{2}{ }^{-}$radical anion formed upon accepting the first electron is adsorbed, followed by oxalate formation $\left(2 \mathrm{CO}_{2}^{--} \rightarrow \mathrm{C}_{2} \mathrm{O}_{4}^{2-}\right)$ or by $\mathrm{CO}$ and $\mathrm{CO}_{3}{ }^{2-}$ formation $\left(2 \mathrm{CO}_{2}^{-} \rightarrow \mathrm{CO}+\mathrm{CO}_{3}^{-}\right)$. In all cases, the determining step of the process is the formation of the radical anion. It is important to note that different studies in aprotic solvents 
show a strong dependence on water presence, even in trace amounts, inducing several changes in the pathway of the $\mathrm{CO}_{2}$ reduction reaction. ${ }^{7,19}$

An important tool for studying $\mathrm{CO}_{2}$ reduction in $\mathrm{ACN}$ media has been infrared spectroelectrochemistry with either external (electrolyte thin layer) ${ }^{22-24}$ or internal $^{22}$ (attenuated total reflection infrared, ATR-IR) configurations. Most of the reports have focused on $\mathrm{Pt}^{25}, \mathrm{Au}$ and glassy carbon electrodes ${ }^{26}$, and more recently on $\mathrm{Cu}, \mathrm{Pt}, \mathrm{Pb}, \mathrm{Au}, \mathrm{Pd}, \mathrm{Ag}^{27}$ and $\mathrm{Sn}^{22}$ electrodes. However, regarding the actual mechanism for $\mathrm{CO}_{2}$ activation and reaction, there is no consensus about band assignment, particularly in the presence of water traces, and the pathway for $\mathrm{CO}_{2}$ reduction is not fully understood yet. Such a pathway, has been reported to have a strong dependence on water content. ${ }^{27-29}$ For instance, with a low water content, IR bands related with the formation of $\mathrm{CO}$ have been reported at less negative potentials than those related to the formation of (bi)carbonates. There is thus a decoupling between (bi)carbonate and $\mathrm{CO}$ formation.

$\mathrm{TiO}_{2}$ is one of the most extensively investigated photocatalyst for $\mathrm{CO}_{2}$ reduction. Many authors have shown the appearance of different products of reduction as a proof of $\mathrm{CO}_{2}$ photoreduction. However, isotope labeling studies have shown that ${ }^{12} \mathrm{C}_{1}$ products were generated even when ${ }^{13} \mathrm{CO}_{2}$ was used as a reactant. ${ }^{30}$ This suggests that the interpretation of the photocatalytic results should be done with caution. On the other hand, the thermodynamic limitations of $\mathrm{TiO}_{2}$ as a reductant should be kept in mind because the conduction band edge is located at a potential less negative $(-0.5 \mathrm{~V}$ vs SHE at $\mathrm{pH} 7)$ than that required for the oneelectron reduction of $\mathrm{CO}_{2}$.

As in our previous work with $\mathrm{WO}_{3},{ }^{31}$ in order to explain the unusual electrochromic effect accompanying $\mathrm{CO}_{2}$ reduction, the model of electrochromism with large cation-containing 
electrolytes proposed by Hepel and coworkers ${ }^{32}$ is adopted, in which other processes such as lattice polarization, dissociative reduction and electrodissolution are taken into account.

\section{EXPERIMENTAL SECTION}

Electrodes for electrochemical studies were prepared on FTO substrates by a spin coating method with suspensions obtained by grinding $1 \mathrm{~g}$ of commercial $\mathrm{TiO}_{2}$ powder (P25 Degussa) in $5 \mathrm{~mL}$ of distilled $\mathrm{H}_{2} \mathrm{O}$, followed by calcination at $450^{\circ} \mathrm{C}$ for $1 \mathrm{~h}$ in air, as previously reported..$^{33}$

All the electrochemical experiments were carried out under the same conditions in a conventional three-electrode glass cell. The supporting electrolyte was 0.1 M tetrabutylammonium perchlorate (TBAP) ( $\geq 99.0 \%$ from Sigma-Aldrich) in ACN $(99.88 \%$ anhydrous from Scharlau, Multisolvent, HPLC grade), which was subjected to a drying procedure with a $3 \AA$ molecular sieve (rods from Sigma-Aldrich) following a reported procedure. ${ }^{34}$ All the potentials in ACN solutions were measured against either a homemade $\mathrm{Ag}^{+} / \mathrm{Ag}$ reference electrode or an $\mathrm{Ag} / \mathrm{AgCl}(\mathrm{s}) / \mathrm{KCl}(\mathrm{aq}, \mathrm{sat})$ reference electrode. A Pt wire was used as a counter electrode in all the experiments. Unless otherwise stated, potentials are referred to the $\mathrm{Ag}^{+} / \mathrm{Ag}$ electrode. The measurements were performed with a computer-controlled microAutolab potentiostat. In all the experiments, the electrolyte was purged with either $\mathrm{N}_{2}($ Alphagaz 99.999\%) or $\mathrm{CO}_{2}$ (Air Liquid, 99.98\%) for 30 min using an ACN trap to prevent solvent evaporation. Potentiostatic electrolysis experiments were carried out at $-1.8 \mathrm{~V}$ for $3 \mathrm{~h}$ in a closed and sealed glass cell with two compartments separated by a Nafion TM membrane NM-117 pretreated before use for the removal of organic impurities. ${ }^{35}$ 
In situ spectroelectrochemical UV/vis measurements were carried out by coupling an electrochemical cell to an UV-vis spectrophotometer (UV-2401 PC Shimadzu). The cell employed for the spectroelectrochemical measurements was equipped with a cuvette fitted at its bottom and mounted on the support of the spectrophotometer sample chamber. To achieve maximum contrast and high transparency, nanostructured $\mathrm{TiO}_{2}$ were prepared in this case by means of a chemical bath deposition method (see SI for details).

ATR-IR experiments were carried out with a Nexus 8700 (Thermo Scientific) spectrometer equipped with an MCT-A detector. In these experiments, a $\mathrm{TiO}_{2}$ nanostructured layer was also generated by chemical bath deposition on a gold-covered silicon prism beveled at $60^{\circ}$ and used as a working electrode (see SI for details). All the spectra were obtained with a resolution of 8 $\mathrm{cm}^{-1}$. One hundred interferograms were collected at each potential using p-polarized light. The resulting spectra, which are referred to the single beam spectrum collected at $0 \mathrm{~V}$, are presented in absorbance units. Thus, positive-going and negative-going bands correspond, respectively, to a gain or loss of the responsible species in the sample spectrum with respect to the reference spectrum.

Finally, $\mathrm{CO}_{2}$ reduction products were determined upon potentiostatic electrolysis at $-1.8 \mathrm{~V}$ for 3h in $0.1 \mathrm{M}$ TBAP/ACN and 0.1 M TBAP/ACN $+0.5 \mathrm{M} \mathrm{H}_{2} \mathrm{O}$ solutions. A Hewlett Packard 5890 gas chromatograph equipped with a thermal conductivity detector (TCD) was employed to measure gas samples produced from electrolysis. Methanol determination was carried out by semiquantitative determination with an Agilent model $6890 \mathrm{~N}$ gas chromatograph coupled to an Agilent 5973 mass selective detector. Detailed information about additional analytic determinations (ion chromatography, ICP-MS) are presented in the SI. 


\section{RESULTS}

\subsection{Electrode characterization}
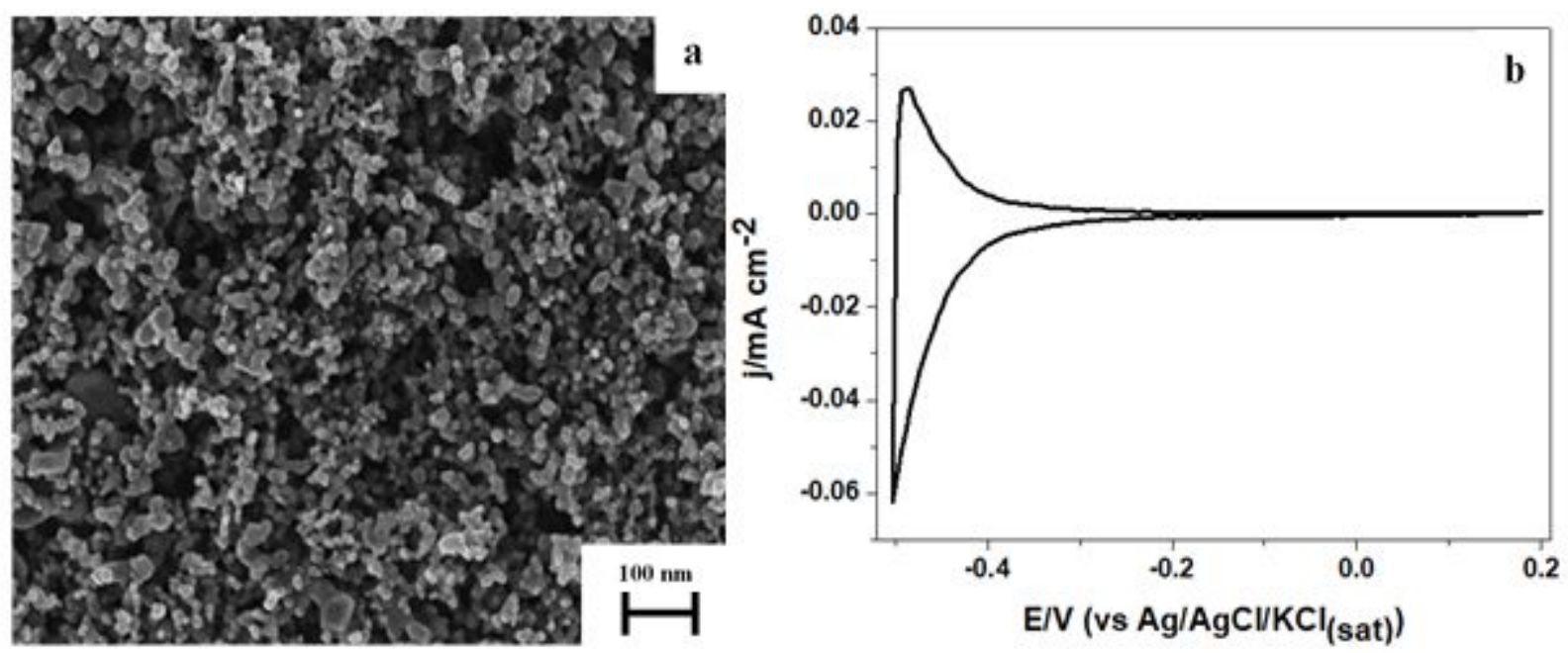

Figure 1. (a) FE-SEM micrograph for an $\mathrm{FTO} / \mathrm{TiO}_{2}$ electrode. (b) Cyclic voltammograms for a $\mathrm{TiO}_{2}$ electrode in aqueous $0.1 \mathrm{M} \mathrm{HClO}_{4}$, purged with $\mathrm{N}_{2}$. Scan rate: $50 \mathrm{mV} \mathrm{s}^{-1}$.

Figure 1a shows a FE-SEM micrograph for a $\mathrm{TiO}_{2}$ electrode, which shows nanoparticles with an average diameter of $20 \mathrm{~nm}$, well distributed over the FTO substrate. Such a nanoparticulate morphology is expected when using slurries prepared from commercial powders. The electrode surface area of the thin film electrodes was assessed by using CV measurements in aqueous $0.1 \mathrm{M} \mathrm{HClO}_{4}$ purged with $\mathrm{N}_{2}$ (Figure 1b). The electrochemical response is characterized by a reversible charge accumulation region. This electron accumulation is accompanied by adsorption/insertion of protons for charge compensation and it is limited to the $\mathrm{TiO}_{2}$ external layer (interfacial region), that is, to the $\mathrm{TiO}_{2}$ region in close vicinity with the electrolyte. 
Importantly, the charge integrated under the $\mathrm{CV}$ in the accumulation region has been shown to be proportional to the interfacial area. ${ }^{33,36,37}$

\subsection{Electrochemical studies}
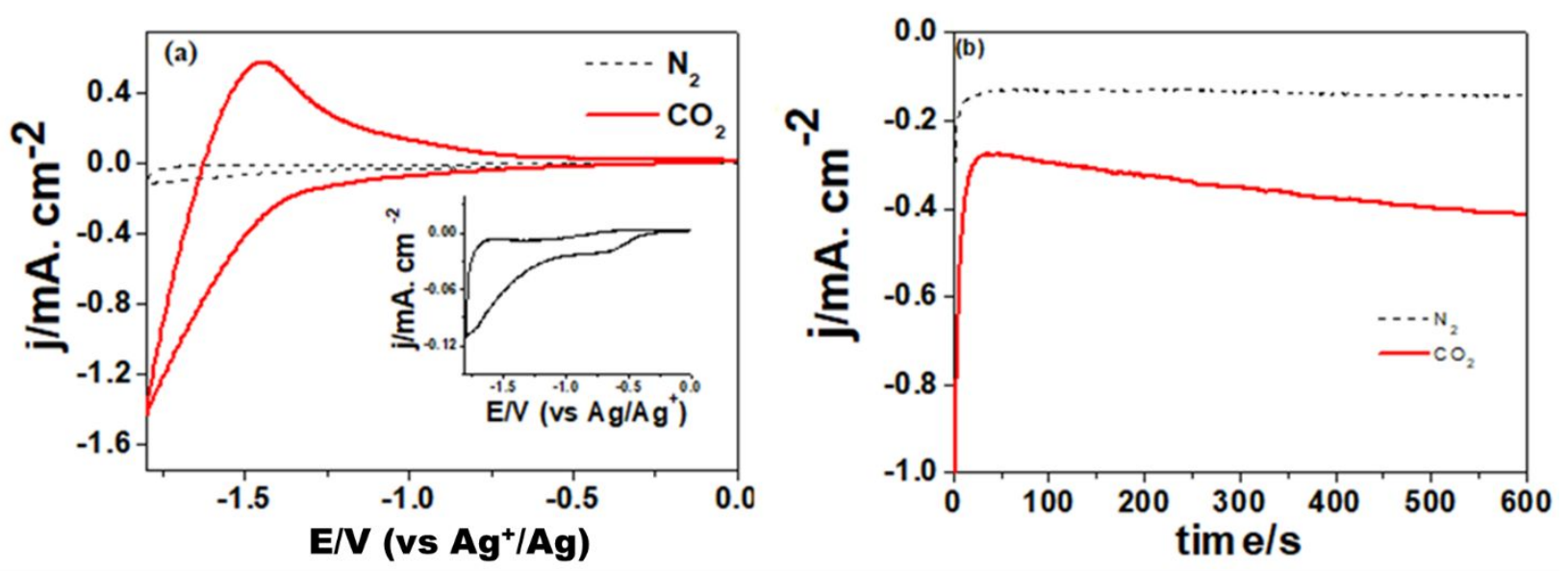

Figure 2. Electrochemical measurements for $\mathrm{FTO} / \mathrm{TiO}_{2}$ electrodes in $0.1 \mathrm{M} \mathrm{TBAP} / \mathrm{ACN}$; a) Cyclic voltammograms at $50 \mathrm{mV} \mathrm{s}^{-1}$. Inset: Enlarged $\mathrm{CV}$ profile for an $\mathrm{N}_{2}$-purged solution; b) Chronoamperograms at an applied potential of $-1.7 \mathrm{~V}$. Black and red curves correspond to the electrolyte purged with either $\mathrm{N}_{2}$ or $\mathrm{CO}_{2}$, respectively.

In Figure 2, both voltammetric and chronoamperometric profiles in the presence and absence of $\mathrm{CO}_{2}$ are shown. First, the potential window for $\mathrm{CO}_{2}$ reduction was determined by recording the corresponding $\mathrm{CV}$ in the nitrogen-purged supporting electrolyte. As shown in Figure 2a, a voltammetric signal appears at $-1.3 \mathrm{~V}$ for the $\mathrm{N}_{2}$-purged solution, corresponding to the beginning of the accumulation region and leading to reduction of $\mathrm{Ti}^{4+}$ to $\mathrm{Ti}^{3+}$ at the $\mathrm{TiO}_{2}$ surface (filling of surface states) (the inset in Figure 2a shows a CV for an $\mathrm{N}_{2}$-purged solution). In this respect, one should consider that tetrabutylammonium cations $\left(\mathrm{TBA}^{+}\right)$are more 
voluminous than the cavity available in $\mathrm{TiO}_{2}$ for intercalation. This fact is important because the formation of oxygen vacancies is favored when intercalation is not possible. This would entail a loss of mass, due to the electrodissolution of $\mathrm{TiO}_{2} \cdot{ }^{38}$

$$
(1+x) \mathrm{TiO}_{2}+2 \mathrm{xe} \rightarrow \mathrm{TiO}_{2-x}+\mathrm{xTiO}_{3}^{2-}
$$

According to Eq. 1, the partial electroreduction of titanium lattice atoms from $\mathrm{Ti}^{+4}$ to $\mathrm{Ti}^{+3}$ induces the formation of oxygen deficient titanium dioxide $\left(\mathrm{TiO}_{2-\mathrm{x}}\right)$ and probably the electrodissolution of $\mathrm{TiO}_{3}^{2-}$ or a similar titanium-containing species.

In $\mathrm{CO}_{2}$-purged solutions, an increase in the cathodic currents associated with $\mathrm{CO}_{2}$ reduction, with an onset at $-1.3 \mathrm{~V}$ vs $\mathrm{Ag} / \mathrm{Ag}^{+}(-0.81 \mathrm{~V}$ vs $\mathrm{SHE}),{ }^{39}$ is observed. Such an onset is close to the beginning of the $\mathrm{TiO}_{2}$ accumulation region, which is, in turn, related to the location of the $\mathrm{TiO}_{2}$ conduction band edge. In this way, the accumulation of charge in surface states through the formation of $\mathrm{Ti}^{3+}$ species, which act as electron-rich centers, plays in favor of $\mathrm{CO}_{2}$ reduction. Interestingly, there is also an increase in the capacitive currents in the accumulation region, even at potentials for which $\mathrm{CO}_{2}$ reduction does not proceed. This suggests important changes in the electrode state that may be associated with an increase in the surface density of $\mathrm{Ti}^{3+}$ species due to an enhancement of the oxygen vacancy generation. In addition, in Fig. $2 \mathrm{~b}$, the current versus time profiles at $-1.7 \mathrm{~V}$ show an increase of the cathodic current densities from $0.14 \mathrm{~mA} \cdot \mathrm{cm}^{-2}$ in the $\mathrm{N}_{2}$-purged solution to values ranging from -0.27 to $-0.42 \mathrm{~mA} \cdot \mathrm{cm}^{-2}$ in the $\mathrm{CO}_{2}$-purged solution, confirming that the increase in the cathodic currents in Fig. 2a does not correspond solely to capacitive processes. It is also apparent that the cathodic current grows over time. 

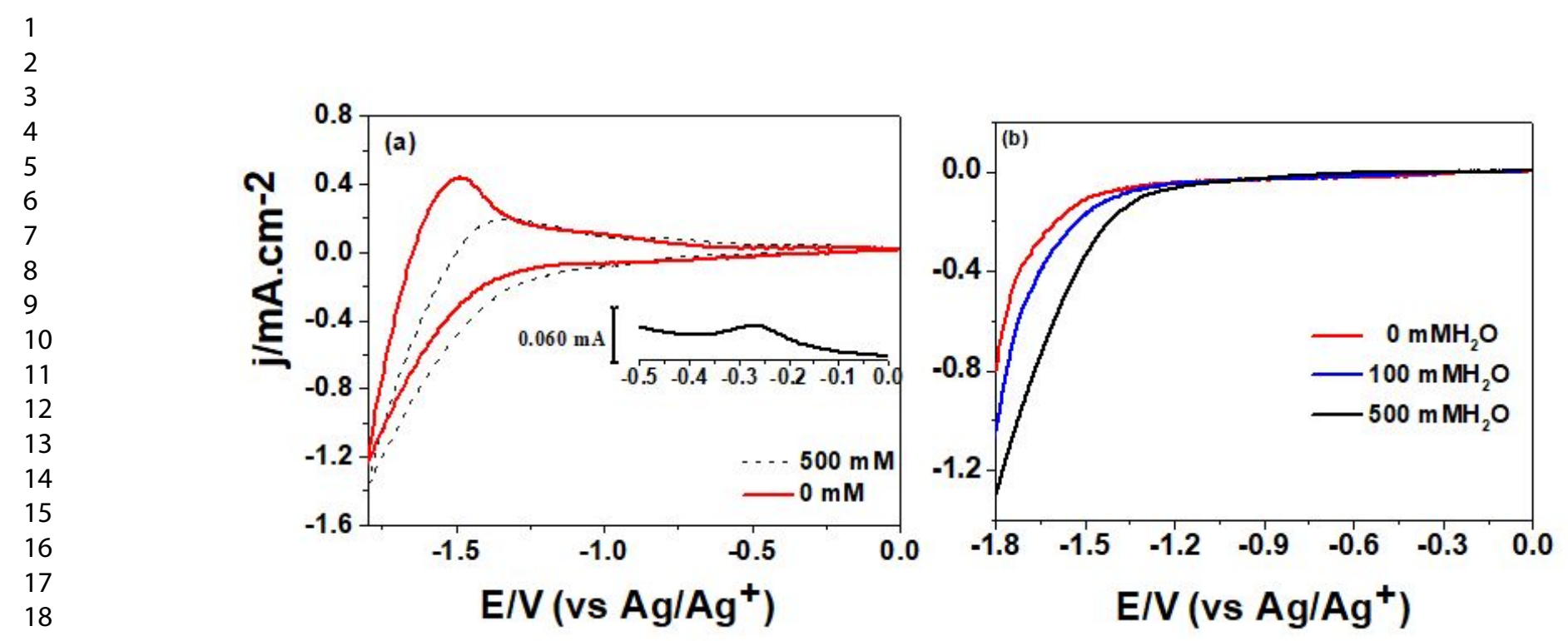

Figure 3. Voltammograms for $\mathrm{FTO} / \mathrm{TiO}_{2}$ electrodes in a $\mathrm{CO}_{2}$-purged $0.1 \mathrm{M}$ TBAP/ACN solution; a) black and red curves correspond to solutions with and without water addition $(0.5$ M). Scan rate: $50 \mathrm{mV} \mathrm{s}^{-1}$; b) LSV with addition of different amounts of water. Scan rate: $5 \mathrm{mV} \mathrm{s}^{-}$ 1. The inset in panel (a) shows an enlarged portion of the CV in the water-containing solution.

In aprotic solvents, traces of water not only change the $\mathrm{CO}_{2}$ reduction reaction path, ${ }^{19,28}$ but also may increase proton concentration, enhancing the intercalation of protons in the $\mathrm{TiO}_{2}$ lattice. Figure 3a shows $\mathrm{CV}$ profiles for $\mathrm{CO}_{2}$-purged solutions with both dry ACN and upon the addition of $0.5 \mathrm{M}$ of water. In the presence of water, the onset of the cathodic currents shifts to less negative potentials, which could be associated to changes in the local $\mathrm{pH}$ because of the existence of an acid-base equilibrium between $\mathrm{CO}_{2}$ and water. In addition, in the positive-going scan, the peak related with the oxidation of $\mathrm{Ti}(\mathrm{III})$ to $\mathrm{Ti}(\mathrm{IV})$ at around $-1,5 \mathrm{~V}$ is clearly diminished. This reflects the stabilization of $\mathrm{Ti}^{3+}$ species, probably through the intercalation of protons in the $\mathrm{TiO}_{2}$ lattice. Figure $3 \mathrm{~b}$ presents linear sweep voltammograms for different water concentrations at a scan rate of $5 \mathrm{mV} \mathrm{s}^{-1}$. Both an increase in the cathodic currents and a shift of their onset toward less negative potentials are observed. This supports the notion of a beneficial 
effect of water on $\mathrm{CO}_{2}$ reduction. Of course, the increase of the cathodic currents could be attributed to water reduction, but in the CV profiles, a new small peak at $-0.25 \mathrm{~V}$ in the positivegoing scan also appears, probably related with the oxidation of a $\mathrm{CO}_{2}$ reduction product (see inset in Fig. 3a). Analogously, chronoamperometric curves confirm the substantial increase of the cathodic current upon the addition of water (see Fig. S1 in the Suppoting Information, SI). Recent results from our laboratory on $\mathrm{CO}_{2}$ reduction at $\mathrm{WO}_{3}$ electrodes have shown that the presence of water change the reduction pathway to $\mathrm{CO}$ and formate generation, in contrast to the case of dry $\mathrm{ACN}$, in which $\mathrm{CO}$ and carbonate were shown to be the main product. ${ }^{31}$

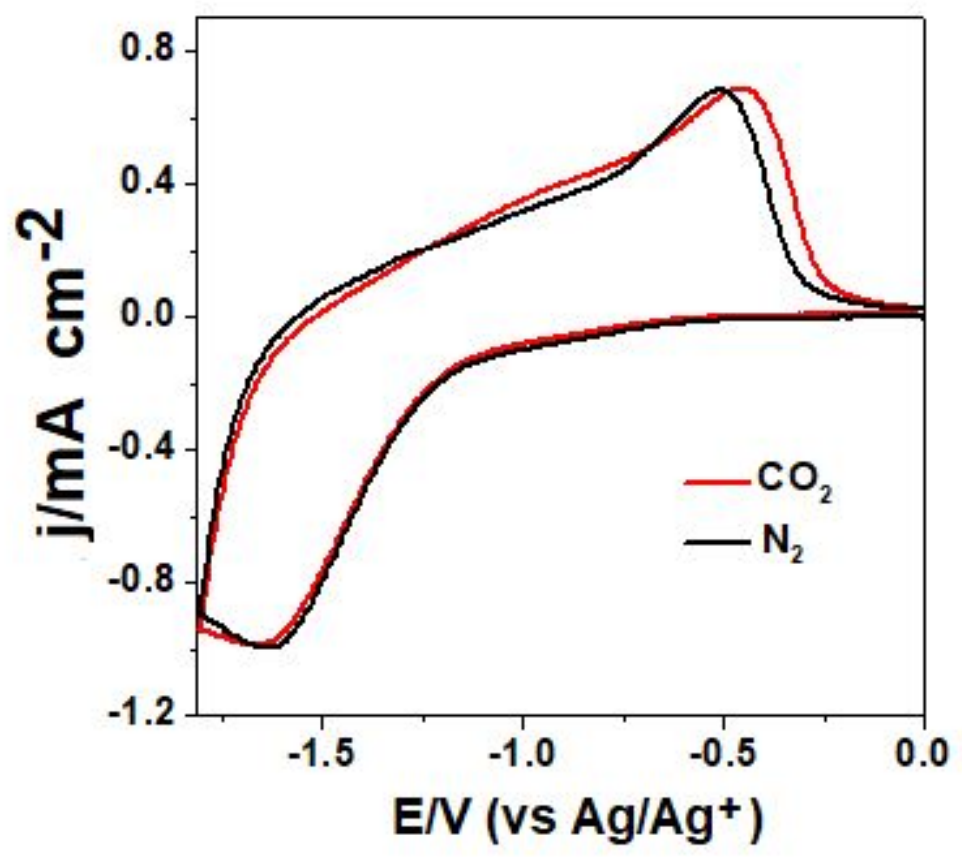

Figure 4. Cyclic voltammograms for an $\mathrm{FTO} / \mathrm{TiO}_{2}$ electrode in $0.1 \mathrm{M} \mathrm{LiClO}_{4} / \mathrm{ACN}$. Black and red curves correspond to the electrolyte purged with $\mathrm{N}_{2}$ and $\mathrm{CO}_{2}$, respectively. Scan rate: 50 $\mathrm{mV} / \mathrm{s}$ 
Figure 4 shows the voltammetric responses for a $\mathrm{TiO}_{2}$ electrode in contact with $0.1 \mathrm{M}$ $\mathrm{LiClO}_{4}$ in $\mathrm{ACN}$ purged with either $\mathrm{N}_{2}$ or $\mathrm{CO}_{2}$. No Faradaic cathodic currents associated with $\mathrm{CO}_{2}$ reduction are observed. This is a general trend reported for other electrode materials such as boron-doped diamond. ${ }^{10}$ These observations have been explained on the basis of $\mathrm{Li}^{+}$inhibiting $\mathrm{CO}_{2}$ reduction by adsorption at the working electrode and formation of hydrophobic layers. ${ }^{40,41}$ In our case, $\mathrm{Li}^{+}$would not only block the adsorption of $\mathrm{CO}_{2}$, precluding the activation of the molecule, but it would also facilitate the stabilization of $\mathrm{Ti}^{3+}$ sites by intercalation into the $\mathrm{TiO}_{2}$ lattice, promoting titanium bronze formation instead of oxygen vacancy formation.

\subsection{UV/vis spectroelectrochemical study}

To follow the density of $\mathrm{Ti}^{3+}$ centers in the $\mathrm{TiO}_{2}$ thin film electrode, in situ UV/vis spectroelectrochemical experiments were carried out. The electrode was first polarized at different potentials between -1.0 and $-1.8 \mathrm{~V}$ for $300 \mathrm{~s}$, followed by $600 \mathrm{~s}$ at open circuit (OC). An interesting observation is the appearance of an intense blue coloration upon negative polarization in a $\mathrm{CO}_{2}$-purged $0.1 \mathrm{M}$ TBAP/ACN working solution. Figure $\mathrm{S} 2$ in the Supporting Information (SI) shows the absorption spectra in the visible for an $\mathrm{FTO} / \mathrm{TiO}_{2}$ electrode in a $\mathrm{CO}_{2}$-purged solution at $-0.3 \mathrm{~V}$ and $-1.8 \mathrm{~V}$ and at $-1.8 \mathrm{~V}$ in an $\mathrm{N}_{2}$-purged solution. A relatively intense and stable broad band is observed at $700 \mathrm{~nm}$ due to electrons localized in surface states (reduction of $\mathrm{Ti}^{4+}$ to $\mathrm{Ti}^{3+}$ in surface states), which is not evident for the $\mathrm{N}_{2}$-purged solution. Based on these observations, spectroelectrochemical experiments were performed at this wavelength.

Table TS1 in the SI gathers the absorbance values obtained after applying different potentials for $300 \mathrm{~s}$ for both $\mathrm{N}_{2}$ and $\mathrm{CO}_{2}$-purged solutions. Note that in all cases the absorbance 
values in $\mathrm{CO}_{2}$-purged solutions are significantly larger than in $\mathrm{N}_{2}$-purged solutions. An enhancement of the electrochromic effect in $\mathrm{CO}_{2}$-purged solutions was seemingly observed for Ramesha et al on $\mathrm{TiO}_{2}$ electrodes under conditions comparable to those employed here. ${ }^{42}$ However, these authors only showed normalized values for absorbance and thus the significant difference existing between $\mathrm{N}_{2}$ and $\mathrm{CO}_{2}$-purged solutions was not dealt with. Electrocatalytic activity was attributed to the reduction of $\mathrm{Ti}^{4+}$ sites to $\mathrm{Ti}^{3+}$ according to:

$$
\left(\mathrm{TiO}_{2}\right) \mathrm{Ti}_{\mathrm{SS}}^{4+}+\mathrm{e} \rightarrow\left(\mathrm{TiO}_{2}\right) \mathrm{Ti}_{\mathrm{sS}}^{3+}
$$

However, the unusual electrochromic effect observed in $\mathrm{CO}_{2}$-purged $\mathrm{ACN}$ solutions is not clarified through Eq. 2.

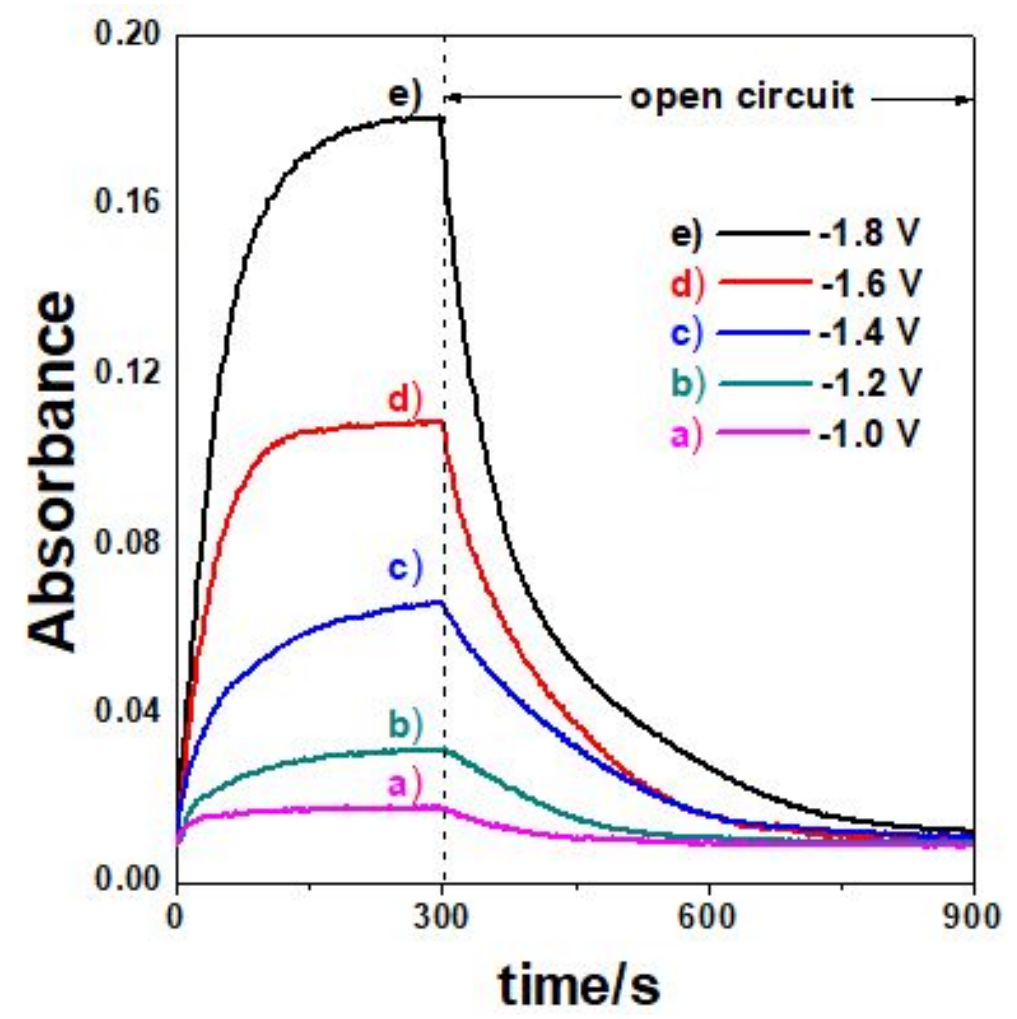

Figure 5. a-e) Absorbance at $700 \mathrm{~nm}$ as a function of time for an $\mathrm{FTO} / \mathrm{TiO}_{2}$ electrode in $0.1 \mathrm{M}$ TBAP/ACN solution; the solution was purged with $\mathrm{CO}_{2}$ for 30 min prior to the measurements. The indicated potentials were applied in the time window from 0 to $300 \mathrm{~s}$. 
Figure 5 shows spectroelectrochemical UV/vis experiments performed in $\mathrm{CO}_{2}$-purged solutions. Not unexpectedly, as the applied potential becomes more negative, the $\mathrm{Ti}^{3+}$ density in $\mathrm{TiO}_{2}$ increases and so do the absorbance values.
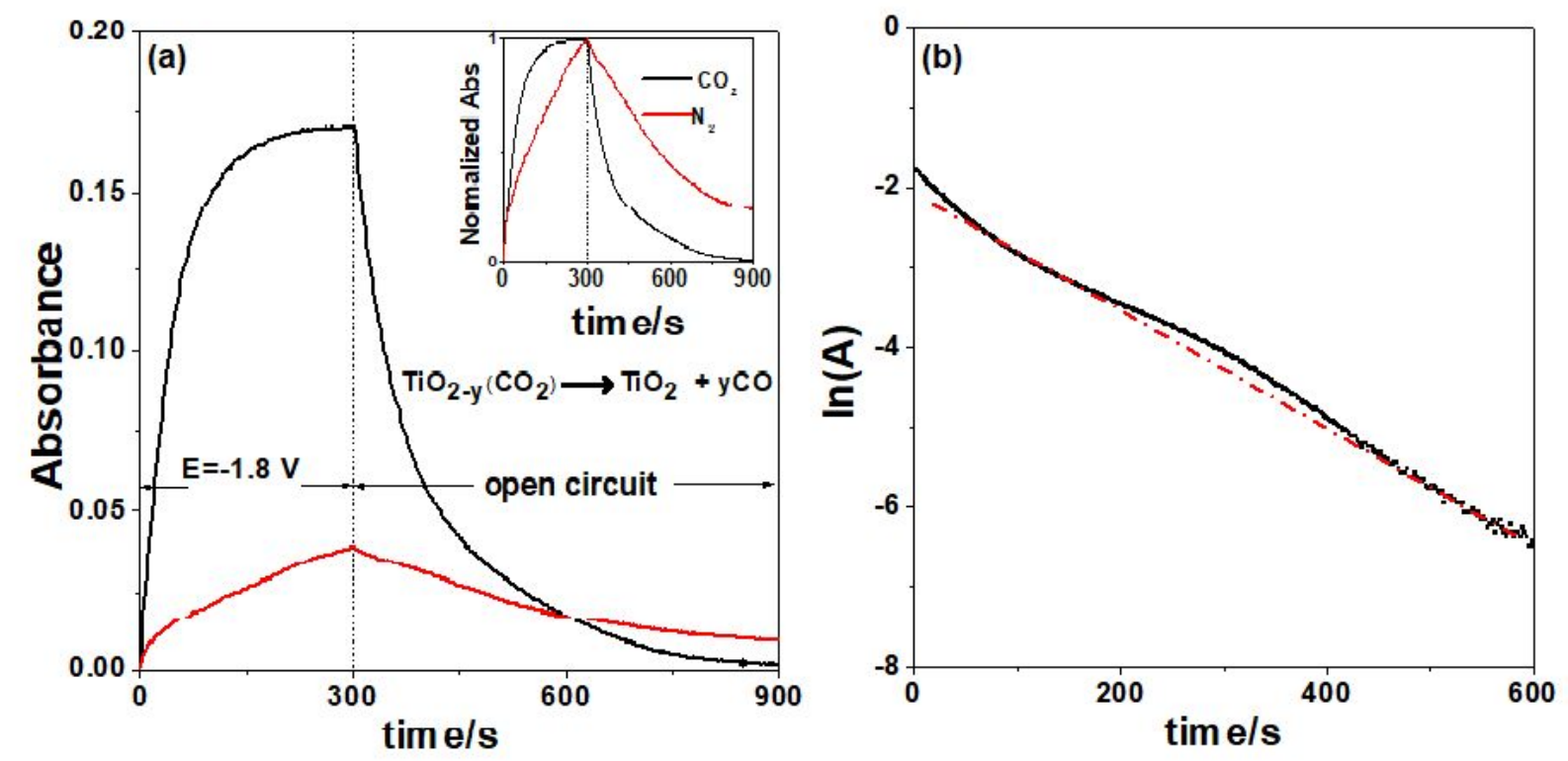

Figure 6. a) Absorbance at $680 \mathrm{~nm}$ vs time for $\mathrm{FTO} / \mathrm{TiO}_{2}$ electrodes in $0.1 \mathrm{M} \mathrm{TBAP} / \mathrm{ACN}$ solutions purged for 30 min with either $\mathrm{N}_{2}$ (red) or $\mathrm{CO}_{2}$ (black). First, a potential of $-1.8 \mathrm{~V}$ was applied for $300 \mathrm{~s}$. Then, open circuit conditions were maintained for $600 \mathrm{~s}$. Inset: normalized absorbance as a function of time. b) Logarithm of absorbance versus time at open circuit in $\mathrm{CO}_{2}-$ purged solution. The red line shows the linear regression for a pseudo-first order kinetics fit.

As observed in Figure 6a, the absorbance builds up after application of a potential of -1.8 $\mathrm{V}$ and subsequently decays at $\mathrm{OC}$ in the presence of either $\mathrm{N}_{2}$ or $\mathrm{CO}_{2}$. However, the maximum absorbance attained is 4 times larger in the presence of $\mathrm{CO}_{2}$ and the bleaching kinetics is faster, revealing the ability of $\mathrm{CO}_{2}$ to scavenge electrons accumulated in the oxide. In fact, at $\mathrm{OC}$, the electrons accumulated in $\mathrm{TiO}_{2}$ are transferred to $\mathrm{CO}_{2}$ molecules and an exponential decay of 
absorbance as a function of time is observed. In figure $6 \mathrm{~b}$, the logarithm of absorbance versus time for the OC period is plotted. A linear tendency indicates a pseudo-first order kinetics for $\mathrm{Ti}^{3+}$ consumption under $\mathrm{CO}_{2}$-purged solution with a constant equal to $0.0078 \mathrm{~s}^{-1}$. This spectroelectrochemical behavior agrees with the results obtained by means of cyclic voltammetry, in which an increase in capacitance is evident when the electrolyte is saturated with $\mathrm{CO}_{2}$, even at potentials at which $\mathrm{CO}_{2}$ reduction does not take place.

\subsection{ATR-IR spectroelectrochemical study}

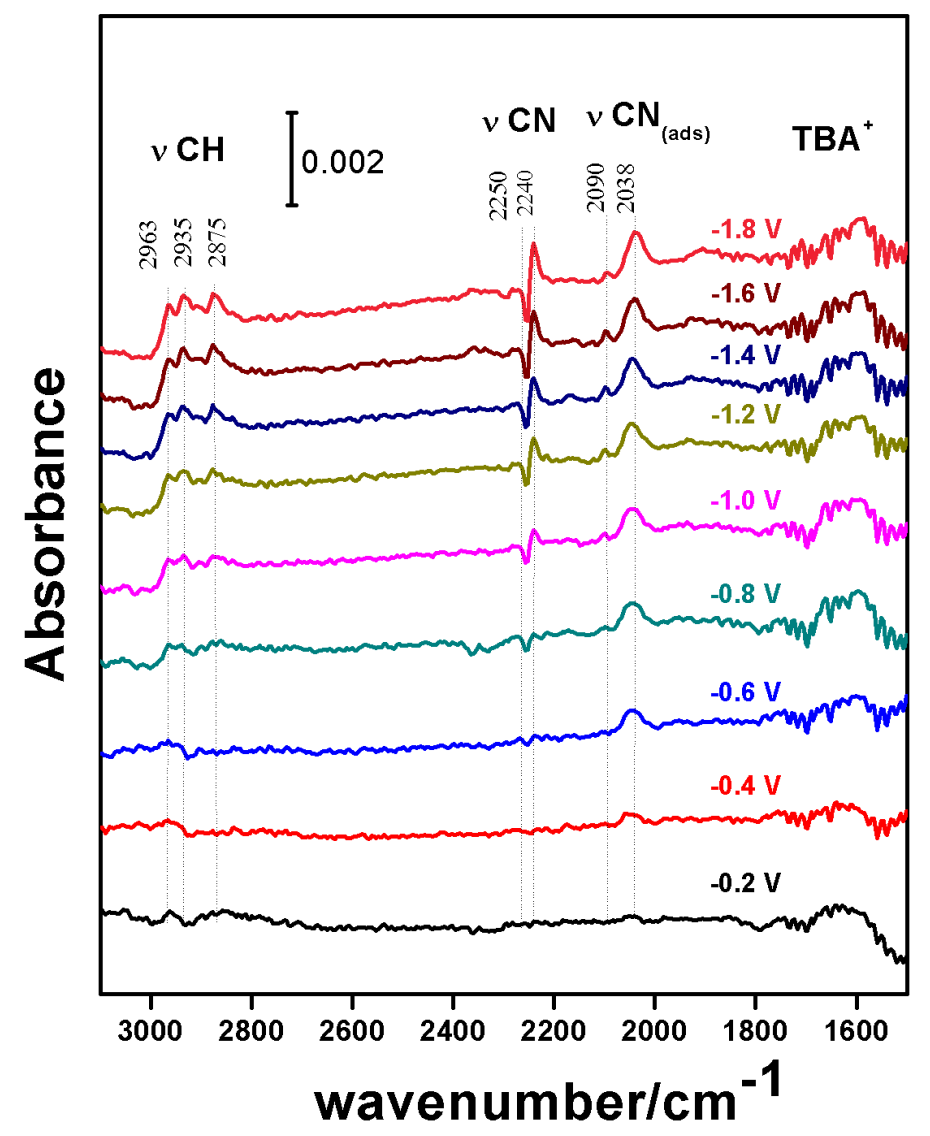

Figure 7. ATR-IR spectra for $\mathrm{TiO}_{2}$ thin film electrodes in an Ar-purged $0.1 \mathrm{M}$ TBAP/ACN solution at different applied potentials; reference potential is $0.0 \mathrm{~V}$ vs $\mathrm{Ag}^{+} / \mathrm{Ag}$. Consecutive spectra are shifted upwards by a constant value for the sake of comparison. 
The vibrational properties of interfacial species can be addressed by in situ ATR-IR spectroelectrochemical measurements. Figure 7 shows ATR-IR spectra from 3100 to $1500 \mathrm{~cm}^{-1}$ in an Ar-purged solution for $\mathrm{TiO}_{2}(\mathrm{P} 25)$ electrodes in $0.1 \mathrm{M}$ TBAP/ACN at different applied potentials from $-0.2 \mathrm{~V}$ to $-1.8 \mathrm{~V}$ (reference spectrum taken at $0.0 \mathrm{~V}$ ). In these spectra, several bands related with the supporting electrolyte can be identified. A $2963 / 2875 \mathrm{~cm}^{-1}$ contribution from the $\mathrm{CH}$ asymmetric and symmetric stretching modes from $\mathrm{CH}_{3}$ in $\mathrm{TBA}^{+}$and $\mathrm{ACN}$ can be distinguished. ${ }^{43,44}$ These bands consistently increase in intensity as more negative potentials are applied, reflecting the accumulation of $\mathrm{TBA}^{+}$cations by electrosorption. In addition, the spectra show a bipolar band centered at $2245 \mathrm{~cm}^{-1}$, which is assigned to the $v(\mathrm{CN})$ of adsorbed ACN. ${ }^{44}$ The shape of this feature reflects the sensitivity of the corresponding band frequency to the electrode potential, and therefore it could be associated with adsorbed ACN. It has been proposed that chemisorbed ACN can present two different states, a donative state, bound through the free electron pair of the nitrogen atom, or an associative state, in which both carbon and nitrogen atoms are bound to the surface. ${ }^{45}$ The negative contribution and the increase of band intensity with decreasing potentials could be tentatively related with a potential-dependent change of orientation of the adsorbed ACN molecule.

In addition, two bands appear at 2038 and $2090 \mathrm{~cm}^{-1}$, whose intensities increase as potential decreases. It is known that acetonitrile may behave as a very weak Brönsted acid, which can interact with surface base sites in transition metal oxides, generating the adsorbed carbanion $\mathrm{CH}_{2} \mathrm{CN}^{-}$, which presents a $v(\mathrm{CN})$ vibration at wavenumbers $150-200 \mathrm{~cm}^{-1}$ below that of the free molecule in liquid $\mathrm{ACN}\left(2265 \mathrm{~cm}^{-1}\right)^{46}$. In the case of $\mathrm{TiO}_{2}$ in gas phase, the $v(\mathrm{CN})$ band has been reported at $2073 \mathrm{~cm}^{-1} 47$. On the other hand, a spectroelectrochemical study on Pt 
electrodes has provided evidence on the formation of the acetonitrile carbanion in cathodic reactions in acetonitrile/tetra-n-butylammonium tetrafluoroborate electrolytes ${ }^{48}$. Based on these precedents, we assign the bands at 2038 and $2090 \mathrm{~cm}^{-1}$ to the generation of adsorbed acetonitrile anions according to:

$$
\mathrm{TiO}_{2}+\mathrm{CH}_{3} \mathrm{CN}+\mathrm{e} \rightarrow \mathrm{TiO}_{2}(\mathrm{H})+\mathrm{CH}_{2} \mathrm{CN}_{\mathrm{ads}}
$$

A reductive and dissociative adsorption of acetonitrile would occur, with adsorption/intercalation of the released proton. It is now understandable why the intensity of the band increases as the potential becomes more negative.

Figure 8a shows ATR-IR spectra between 2300 and $1150 \mathrm{~cm}^{-1}$ for a $\mathrm{TiO}_{2}$ electrode in contact with a $\mathrm{CO}_{2}$-purged solution at different applied potentials (from -0.2 to $-1.8 \mathrm{~V}$ ). As the potential decreases, there is a shift of the baseline toward higher absorbance values at lower wavenumbers, being thus this effect most pronounced when the electrode is biased at $-1.8 \mathrm{~V}$. This behavior has been previously observed in (photo)electrochemical studies with $\mathrm{TiO}_{2}$ thin films and is related to the accumulation of electrons in the oxide associated with the upward displacement of the Fermi level as potentials decrease. ${ }^{49}$ Interestingly, the baseline shift observed in the presence of $\mathrm{CO}_{2}$ for wavenumbers below ca. $1600 \mathrm{~cm}-1$ is minor in its absence (not shown in Figure 7). From a comparison of Figs. $2 \mathrm{a}$ and $8 \mathrm{a}$, it is apparent that the enhancement in the capacitive voltammetric currents agrees well with an increase in the baseline shift. 


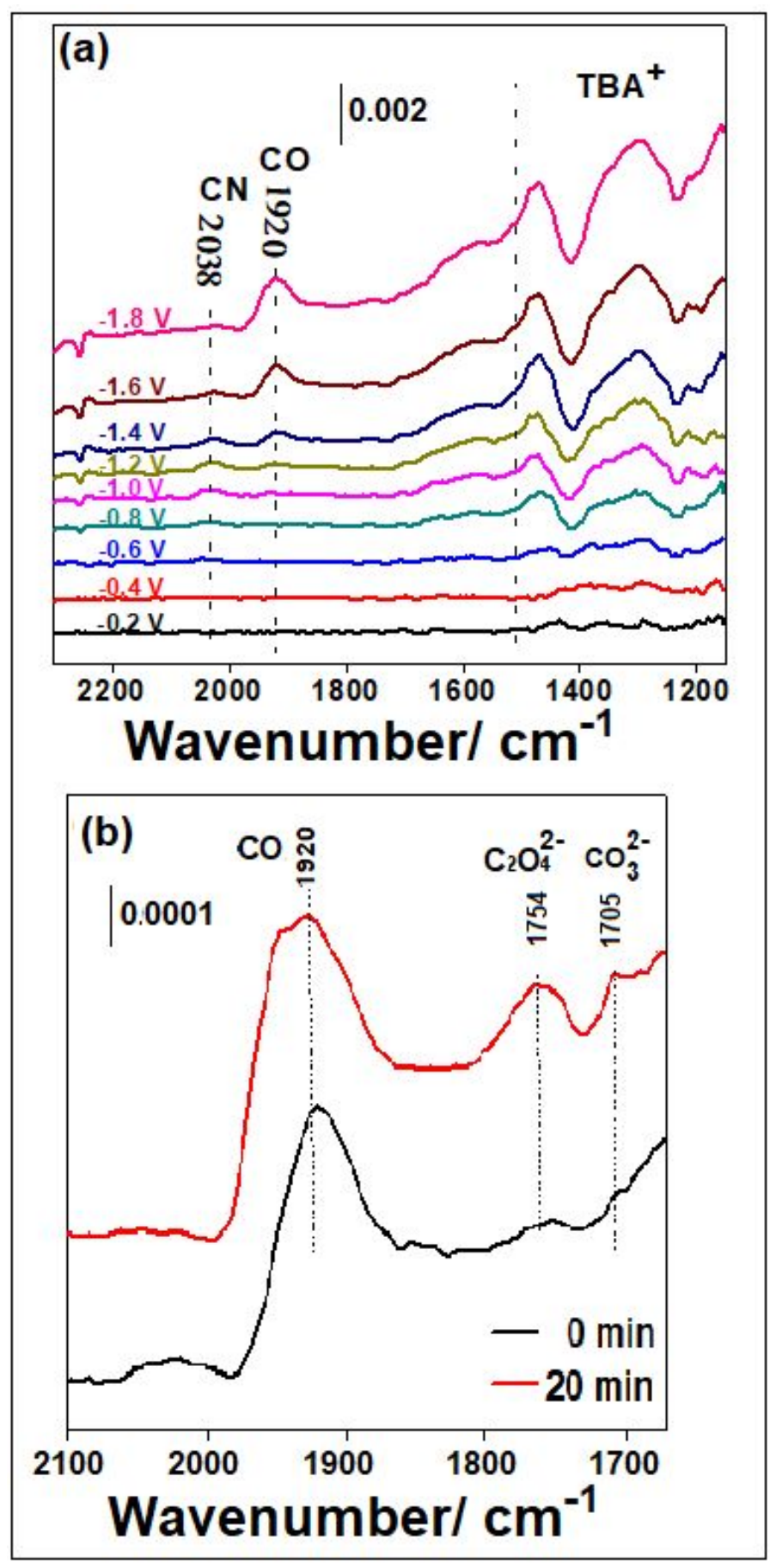

Figure 8. a) ATR-IR spectra for $\mathrm{TiO}_{2}$ thin film electrodes in $\mathrm{CO}_{2}$-purged $0.1 \mathrm{M}$ TBAP /ACN solutions at different potentials; reference potential is $0.0 \mathrm{~V}\left(\mathrm{vs} \mathrm{Ag} / \mathrm{Ag}^{+}\right)$; b) Enlarged ATR-IR spectra in the carboxyl region at times 0 and 20 min upon application of a potential of $1.80 \mathrm{~V}$. 
Fig. 8a shows a band at $1920 \mathrm{~cm}^{-1}$ probably related with the stretching vibration of adsorbed $\mathrm{CO}$. This band appears at potentials more negative than $-1.2 \mathrm{~V}$ in agreement with the onset potential for the appearance of Faradaic currents related with $\mathrm{CO}_{2}$ reduction. FT-IR studies on gaseous $\mathrm{CO}$ adsorption on $\mathrm{TiO}_{2}$ have shown bands at 2050-2110 $\mathrm{cm}^{-1}$ related with $\mathrm{CO}$ bound to $\mathrm{Ti}^{4+} .50$ However, the band at $1920 \mathrm{~cm}^{-1}$ related with the adsorption of $\mathrm{CO}$ in the electrochemical environment has a wavenumber lower than expected; revealing that $\mathrm{CO}$ bound to $\mathrm{TiO}_{2}$ at negative applied potentials is likely affected by the presence of a high density of oxygen vacancies and $\mathrm{Ti}^{3+}$ sites. The $\mathrm{C}-\mathrm{O}$ stretching frequency for $\mathrm{CO}$ adsorbed at $\mathrm{Ti}^{3+}$ sites on $\mathrm{TiO}_{2}$ is expected to be lower than that of gaseous $\mathrm{CO}$, due to an important electron donation from occupied $d$ orbitals of the metal to empty $\mathrm{O} 2 \mathrm{p} \pi$-antibonding orbitals in the $\mathrm{CO}$ molecule ${ }^{51}$. Admittedly, and as far as we know, such a low value for the adsorbed CO stretching frequency has not been reported in published experimental studies. However, published theoretical results support our tentative assignment ${ }^{52}$. In this work, the authors calculate that in defective anatase surface, the $v(\mathrm{CO})$ frequency would significantly redshift down to a value of $1936 \mathrm{~cm}^{-1}$, particularly for adsorption on a $\mathrm{Ti}^{3+}$ site associated to a bridging oxygen vacancy. The electrochemical environment would be particularly prone to showing this adsorption mode as the negative applied potential and the presence of $\mathrm{CO}_{2}$ would extraordinarily favor the attainment of a high density of oxygen vacancies. It is worth noting that the development of the $\mathrm{CO}$ band is paralleled by the observation of bands at ca. $2240 \mathrm{~cm}^{-1}$ (see Figure 8a). In contrast with the bipolar features in Figure 7, suggesting a potential-dependent reorientation of adsorbed CAN molecules (vide supra), the bands at ca. $2240 \mathrm{~cm}^{-1}$ in the $\mathrm{CO}_{2}$-containing ACN solution are negative, thus indicating the displacement of adsorbed CAN upon $\mathrm{CO}$ adsorption. 
Figure $8 \mathrm{~b}$ allows the comparison, in the spectral carboxyl region between 2100 and 1680 $\mathrm{cm}^{-1}$, for ATR-IR spectra acquired in $\mathrm{CO}_{2}$-purged solutions immediately after applying a potential of $-1.80 \mathrm{~V}$ and after $20 \mathrm{~min}$ of polarization. Both the band assigned to adsorbed $\mathrm{CO}$ at $1920 \mathrm{~cm}^{-1}$ and that at $1754 \mathrm{~cm}^{-1}$ associated with oxalic acid formation (due to residual water in solution), develop over time. In addition, a small band at $1705 \mathrm{~cm}^{-1}$ is clearly distinguished, in particular for a time of $20 \mathrm{~min}$, and it is probably related with carbonate formation. Carbonate anions have an $D_{3 h}$ symmetry and are expected to have three active modes in IR; however, adsorbed carbonate can be associated to either a monodentate or a bidentate configuration, inducing a change in the symmetry and the vibrational modes of the carbonate species. In a recent study of $\mathrm{CO}_{2}$ reduction on copper electrodes in $\mathrm{ACN}$, tetraethylammonium carbonate, formate and oxalate salts were used as patrons for IR band assignment in the carbonyl group region. The $\mathrm{C}=\mathrm{O}$ vibration exhibits two distinguishable bands at 1681 and $1641 \mathrm{~cm}^{-1}$ for (bi)carbonate species, but only one at 1586 and $1569 \mathrm{~cm}^{-1}$ for formate and oxalate, respectively. ${ }^{27}$ In our ATR-IR spectra, a broad band at 1570 is observed. On this basis, we could tentatively assign this broad band at $1570 \mathrm{~cm}^{-1}$ to the $\mathrm{C}=\mathrm{O}$ vibration of carbonyl groups in oxalate.

On the other hand, the fact that the band related with carbonate anion appears later than the $\mathrm{CO}$ band, can be related with the decoupling of $\mathrm{CO}$ and carbonate formation because of the presence of residual water in solution ${ }^{27}$ or through $\mathrm{TiO}_{2}$ regeneration, according to the model described below. This behavior is in contrast with the classic mechanism proposed for metal electrodes in aprotic solvents, in which the formation of $\mathrm{CO}$ and carbonate happen simultaneously. ${ }^{20}$

\subsection{Determination of $\mathrm{CO}_{2}$ reduction products.}


$\mathrm{CO}_{2}$ reduction products were determined upon potentiostatic electrolysis at $-1.8 \mathrm{~V}$ for $3 \mathrm{~h}$ in both $0.1 \mathrm{M}$ TBAP/ACN and 0.1 M TBAP/ACN $+0.5 \mathrm{M} \mathrm{H}_{2} \mathrm{O}$ solutions. Figures S3 and S4 show potentiostatic electrolysis I-t and Q-t profiles for both dry ACN and ACN $+0.5 \mathrm{M} \mathrm{H}_{2} \mathrm{O}$ solutions. In table 1, a summary of the products determined with different analytical techniques is presented.

Table 1. Summary of the $\mathrm{CO}_{2}$ reduction products for potentiostatic electrolysis at $-1.8 \mathrm{~V}$ in $0.1 \mathrm{M}$ TBAP/ACN and 0.1 M TBAP + 0.5 $\mathrm{M} \mathrm{H}_{2} \mathrm{O} / \mathrm{ACN}$ solutions. N.D.: not detected.

\begin{tabular}{|c|c|c|c|}
\hline \multirow{2}{*}{ Product } & \multicolumn{2}{|c|}{ Faradaic efficiency } & \multirow{2}{*}{ Technique } \\
\cline { 2 - 3 } & $\begin{array}{c}\text { dry } \\
\text { acetonitrile }\end{array}$ & $\begin{array}{c}\text { acetonitrile }+\mathbf{0 . 5} \mathbf{~ M} \\
\mathbf{H}_{\mathbf{2}} \mathbf{O}\end{array}$ & GC -TCD \\
\hline Carbon monoxide & $48 \%$ & $12 \%$ & IC \\
\hline Oxalate & $12 \%$ & N.D. & GC-MS \\
\hline Methanol & N.D. & $60 \%$ & ATR IR \\
\hline Carbonate & N.D. & N.D. & ICP-MS \\
\hline Titanium & $0.19 \%$ & N.D. & . \\
\hline
\end{tabular}

Figure S5 in the SI shows the GC-TCD chromatograms for the injection of a CO patron and a $250 \mu \mathrm{L}$ sample from the headspace of the working electrode compartment. Air and $\mathrm{CO}_{2}$ patrons were injected and no signal were detected at the retention time of the $\mathrm{CO}$ patron. Figure S6 shows ion chromatograms (IC) for the injection of oxalate patrons as well as for the working solution after $1.5 \mathrm{~h}$ of electrolysis. Figure S7 shows GC-MS chromatograms for the injection of both a methanol patron and sample from the catholite solution after $75 \mathrm{~min}$ of electrolysis. ICPMS results confirm the presence of titanium in the catholyte. Adittional quantitative information is shown in tables TS2 and TS3 in the SI. 


\section{DISCUSSION}

Based on the results presented above, a model for $\mathrm{CO}_{2}$ reduction on $\mathrm{TiO}_{2}$ electrodes with large-cation electrolytes has been developed. An analogous model was previously proposed for $\mathrm{WO}_{3}$ electrodes in acetonitrile solutions, providing an explanation for the direct relationship existing between an enhanced electrochromic effect and $\mathrm{CO}_{2}$ reduction. ${ }^{31}$ In this section, after some electrochemical considerations, a model for $\mathrm{CO}_{2}$ reduction on $\mathrm{TiO}_{2}$ electrodes is first presented, offering an explanation for both the catalytic behavior for $\mathrm{CO}_{2}$ reduction and the concomitant enhanced electrochromic effect observed. Next, the UV-vis absorbance decay at open circuit potential is analyzed in detail and shown to include kinetic information for $\mathrm{CO}_{2}$ reduction on $\mathrm{TiO}_{2}$ electrodes. Finally, a brief discussion on the $\mathrm{CO}_{2}$ reduction products in both dry and humid ACN is presented.

Faradaic currents appear with an onset potential of $-1.3 \mathrm{~V}$ vs. $\mathrm{Ag}^{+} / \mathrm{Ag}$ (which corresponds to a potential value of $-0.81 \mathrm{~V}$ vs $\mathrm{SHE}$ (see $\mathrm{SI}$ )) for $\mathrm{CO}_{2}$ reduction on $\mathrm{TiO}_{2}$ electrodes in dry ACN solutions. This reflects a decrease in the overpotential expected for the first electron transfer in $\mathrm{CO}_{2}$ reduction, which requires, in principle, a potential more negative than $-1.97 \mathrm{~V}$ (vs. SHE) in aprotic solvents (couple $\left.\mathrm{CO}_{2} / \mathrm{CO}_{2}^{-}\right) \cdot{ }^{53}$ This decrease has been related to the activation of the $\mathrm{CO}_{2}$ molecule by adsorption on $\mathrm{TiO}_{2}$ with the formation of charged species ( $\mathrm{CO}_{2}^{\delta \cdot-}$ ). The interaction of the $\mathrm{CO}_{2}$ molecule with the surface induces several changes due to a bending of the linear geometry of the $\mathrm{CO}_{2}$ molecule. Specifically, a diminution in the $\mathrm{O}-\mathrm{C}-\mathrm{O}$ bond angle, leads to a decrease of the $\mathrm{CO}_{2}$ LUMO level through electron density donation. In particular, a decrease of $0.14 \mathrm{eV}$ in the energy of the LUMO level with a change in the O-C-O angle from $180^{\circ}$ to $170^{\circ}$ has been reported..$^{13,54}$ 
The reduction of $\mathrm{Ti}^{4+}$ to $\mathrm{Ti}^{3+}$ sites is facilitated by the presence of $\mathrm{CO}_{2}$ in solution. The enhancement of the capacitive currents in the CV profiles indicates an increase in the density of surface states located below the conduction band of $\mathrm{TiO}_{2}$. This fact can be rationalized by the formation of oxygen vacancies caused by the application of increasingly negative potentials. In this way, the chemisorption of $\mathrm{CO}_{2}$ could not only induce the activation of the $\mathrm{CO}_{2}$ molecule, but also the stabilization of electron-rich $\mathrm{Ti}^{3+}$ centers. Sorescu et al. found that oxygen vacancies considerably influence the adsorption properties of $\mathrm{CO}_{2}$ on rutile (110) and anatase (101) surfaces, and they anticipated that these defects play an important role in the complex surface chemistry of the $\mathrm{CO}_{2}$ reduction catalysis. ${ }^{55}$ Consistently, studies on $\mathrm{CO}_{2}$ reduction show that the activation energy for $\mathrm{CO}_{2}$ desorption from $\mathrm{Ti}^{3+}$ sites is higher than that from $\mathrm{Ti}^{4+}$ sites. ${ }^{56}$ This suggests that $\mathrm{CO}_{2}$ is more strongly bound to $\mathrm{Ti}^{3+}$ than $\mathrm{Ti}^{4+}$ sites. In addition, it has been shown that reduced $\mathrm{TiO}_{2}$ consistently has a higher catalytic activity for the reduction of $\mathrm{CO}_{2}$, as the presence of point defects provides a higher density of active sites. ${ }^{57}$ In scheme 1 , the adsorption of $\mathrm{CO}_{2}$ on $\mathrm{TiO}_{2}$ electrodes with i) a downshift of the LUMO level, ii) electron transfer from $\mathrm{TiO}_{2}$ to the $\mathrm{CO}_{2}$ molecule, and iii) the subsequent enhancement of the density of surface states are sketched. 


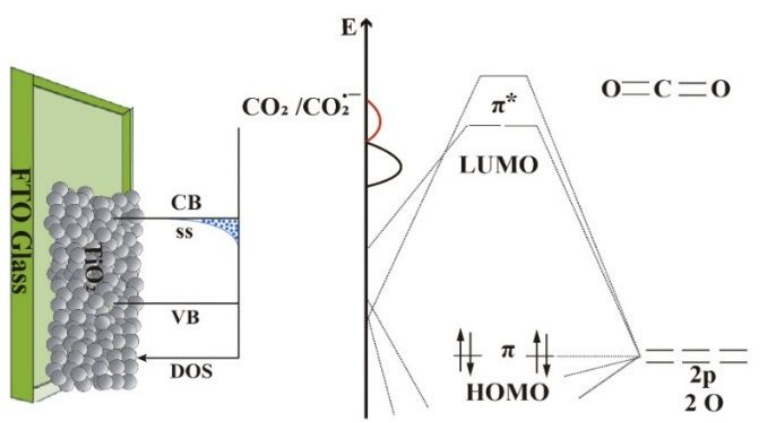

Scheme 1. Schematic representation of the different processes associated with the adsorption of $\mathrm{CO}_{2}$ molecules on $\mathrm{TiO}_{2}$ and the application of a negative potential.

Based on the previously published dissociative model for the electroreduction of $\mathrm{CO}_{2},{ }^{31}$ one may explain the enhancement of the capacitive currents observed in the CV profiles (even at potentials at which $\mathrm{CO}_{2}$ reduction does not proceed). In this way, $\mathrm{CO}_{2}$ reduction begins with the electrosorption of $\mathrm{CO}_{2}$ over $\mathrm{TiO}_{2}$ according to:

$$
(1+\mathrm{y}) \mathrm{TiO}_{2}+\mathrm{yCO}_{2}+2 \mathrm{ye} \rightleftharpoons \mathrm{TiO}_{2-\mathrm{y}}\left(\mathrm{CO}_{2}\right)_{y}+\mathrm{yTiO}_{3}^{2-}
$$

In Eq. 4, the coefficient $y$ is expected to be significantly larger than coefficient $x$ in Eq. 1. It is worth noting that the electrosorption of the $\mathrm{CO}_{2}$ molecule with concomitant partial oxide electrodissolution as $\mathrm{TiO}_{3}^{2-}$ is thought to be restricted to the interfacial region, without significant structural damage in the subsurface region of the $\mathrm{TiO}_{2}$ film..$^{32}$ Thus, the formation of 
the adsorbate $\mathrm{TiO}_{2-\mathrm{y}}\left(\mathrm{CO}_{2}\right)_{y}$ induces several modifications in the interface, which are reflected in the development of capacitive currents promoting the generation of non-stoichiometric $\mathrm{TiO}_{2-\mathrm{y}}$, together with the formation of $\mathrm{TiO}_{3}^{2-}$ species. This behavior would point to a synergistic effect between the $\mathrm{CO}_{2}$ molecule and the surface: electrosorption triggers the activation of the $\mathrm{CO}_{2}$ molecule together with the promotion of oxygen vacancies.

When the potential decreases below $-1.3 \mathrm{~V}(-0.81 \mathrm{~V}$ vs SHE), the resulting high concentration of localized electrons (as $\mathrm{Ti}^{3+}$ sites) at the surface region plays in favor of electron transfer to adsorbed $\mathrm{CO}_{2}$ molecules. Thus, the appearance of Faradaic currents related with the products of $\mathrm{CO}_{2}$ reduction is observed. ATR-IR spectra show that the development of a broad band related with $\mathrm{CO}$ generation coincides with the onset potential of the Faradaic currents. Interestingly, the presence of a band at $1925 \mathrm{~cm}^{-1}$ assigned to the stretching vibration of CO adsorbed in a bridge configuration provides evidence for the generation of the adsorbed species $\mathrm{TiO}_{2-\mathrm{y}}(\mathrm{CO})_{y}$. This process is accompanied by a depletion of ACN molecules in the interface, suggesting the substitution of $\mathrm{ACN}$ molecules by the $\mathrm{CO}_{2}$ reduction products. The processes of $\mathrm{CO}$ adsorbate formation, $\mathrm{CO}$ generation and electrodissolution of $\mathrm{TiO}_{3}^{2-}$ would be described according to:

$$
\begin{gathered}
(1+\mathrm{y}) \mathrm{TiO}_{2-\mathrm{y}}\left(\mathrm{CO}_{2}\right)_{y}+2 y e \rightarrow \mathrm{TiO}_{2-\mathrm{y}}(\mathrm{CO})_{y(1+y)}+\mathrm{yTiO}_{3}^{2-} \\
\mathrm{TiO}_{2-\mathrm{y}}(\mathrm{CO})_{y(1+y)} \rightarrow \mathrm{TiO}_{2-\mathrm{y}}+y(1+y) \mathrm{CO}
\end{gathered}
$$

The global equation for $\mathrm{CO}_{2}$ reduction (concomitant with electrodissolution of $\mathrm{TiO}_{2}$ ) would result from the sum of Eqs. 4 to 6: 


$$
(1+\mathrm{y})^{2} \mathrm{TiO}_{2}+\mathrm{y}(1+\mathrm{y}) \mathrm{CO}_{2}+2 y(2+y) e \rightarrow \mathrm{TiO}_{2-\mathrm{y}}+\mathrm{y}(1+\mathrm{y}) \mathrm{CO}+\mathrm{y}(2+\mathrm{y}) \mathrm{TiO}_{3}^{2-}
$$

The partial electroreduction of $\mathrm{TiO}_{2}$ in $\mathrm{CO}_{2}$-purged solutions induces several changes: i) a shift of the Fermi level, which approaches the conduction band edge, ii) an increase in the UV/vis absorbance values as shown by the spectroelectrochemical measurements and, iii) a displacement of the baseline in the ATR-IR spectroelectrochemical measurements. The partial electroreduction of $\mathrm{TiO}_{2}$ implies that it suffers a corrosion (through $\mathrm{TiO}_{3}^{2}$ - formation) tantamount to $\mathrm{CO}_{2}$ reduction (or $\mathrm{CO}$ generation) according to Eq. 7. The results shown in table TS4 in the SI for ICP-MS analysis confirm the presence of titanium in the working solution after electrolysis, supporting partial electrodissolution of the $\mathrm{TiO}_{2}$ electrode. However, a concentration of titanium around 3 orders of magnitude lower than that expected based on Eq. (7) was detected. Importantly, the concentration of titanium in solution does not increase after $3 \mathrm{~h}$ of electrolysis. This suggests that $\mathrm{TiO}_{2}$ is not a reactant and that $\mathrm{TiO}_{3}^{2-}$ species are recovered to $\mathrm{TiO}_{2}$ in the presence of $\mathrm{CO}_{2}$ in a process accompanied by carbonate formation according to:

$$
\mathrm{TiO}_{2-\mathrm{y}}+\mathrm{y}(2+\mathrm{y}) \mathrm{TiO}_{3}^{2-}+\mathrm{y}(1+\mathrm{y}) \mathrm{CO}_{2} \rightarrow(1+\mathrm{y})^{2} \mathrm{TiO}_{2}+\mathrm{y}(1+\mathrm{y}) \mathrm{CO}_{3}^{2-}+2 \mathrm{ye}
$$

This mechanism leads to a gradual renewal of the surface via electrodissolution/deposition of $\mathrm{TiO}_{2}$. An evaluation of the specific interfacial area of the $\mathrm{TiO}_{2}$ electrodes using $\mathrm{CV}$ measurements in aqueous $0.1 \mathrm{M} \mathrm{HClO}_{4}$ solutions before and after the electrolysis of the $\mathrm{CO}_{2}$ purged solution was also carried out (Fig S8). Clearly, after electrolysis at $-1.8 \mathrm{~V}$ for $3 \mathrm{~h}$, the accumulation region is larger, specifically by a $46 \%$, confirming an increase in interfacial electroactive area. The formation of $\mathrm{TiO}_{3}{ }^{2-}$ from $\mathrm{TiO}_{2}$ in the presence of $\mathrm{CO}_{2}$ has been identified in molten carbonate fuel cells by means of XPS measurements. ${ }^{58}$ 
It is also worth noting that this model for the electrocatalytic reduction of $\mathrm{CO}_{2}$ helps to rationalize the growth of the reduction current over time (see Fig. 2b). It is likely that, as electrolysis progresses, the density of surface oxygen vacancies increases. Taking into account that these are considered to be the active sites for $\mathrm{CO}_{2}$ reduction, this would lead to the monotonous enhancement of the $\mathrm{CO}_{2}$ reduction process.

The model presented above rationalizes the electrocatalytic behavior of the $\mathrm{TiO}_{2}$ electrodes. In addition, an enhanced electrochromic effect (higher absorbance values) is observed in $\mathrm{CO}_{2}$-purged solutions, which can be interpreted as a result of an increase in the density of $\mathrm{Ti}^{3+}$ centers and oxygen vacancies. However, when the electrode is maintained at open circuit the absorbance decays in $\mathrm{CO}_{2}$-purged solutions at a faster rate than in $\mathrm{N}_{2}$-purged solutions (Fig. 6). This confirms that the $\mathrm{CO}_{2}$ molecule can act as an electron scavenger in nonstoichiometric $\mathrm{TiO}_{2-}$ y. In this situation, the oxygen deficiency could be alleviated by oxygen from adsorbed $\mathrm{CO}_{2}$ molecules, leading to the possibility of exothermic dissociation of $\mathrm{CO}_{2}$ with $\mathrm{CO}$ formation and reoxidation of the $\mathrm{TiO}_{2}$ surface

$$
\mathrm{TiO}_{2-y}\left(\mathrm{CO}_{2}\right)_{y} \rightarrow \mathrm{TiO}_{2}+\mathrm{yCO}
$$

It is worth noting that the exothermic dissociation of $\mathrm{CO}_{2}$ with $\mathrm{CO}$ formation has been observed by Lee et al. using scanning tunneling microscopy (STM). They have shown that electron injection from the STM tip into adsorbed $\mathrm{CO}_{2}$ induces the dissociation of $\mathrm{CO}_{2}$ with $\mathrm{CO}$ formation. ${ }^{59}$ Importantly, the oxygen vacancy defect on $\mathrm{TiO}_{2}$ anatase is healed by the oxygen atom released during the dissociation process.

A pseudo-first order reaction was determined for the decay of the species responsible for coloration $\left(\mathrm{Ti}^{3+}\right)$ when the $\mathrm{FTO} / \mathrm{TiO}_{2}$ electrode is first biased at $-1.8 \mathrm{~V}$ and then maintained at 
OC (see Figure 6). In Fig. S9 in the SI, the logarithm of the absorbance is plotted against time for different initial potentials and the same polarization time. A linear behavior, corresponding to a pseudo-first order reaction, is consistently observed. Table 2 gathers the corresponding kinetic constant values.

Table 2. Rate constant values for the pseudo-first order reaction of consumption of $\mathrm{TiO}_{2-\mathrm{y}}$; the corresponding plots are shown in Fig. S9.

\begin{tabular}{|c|c|}
\hline Applied potential & Constant rate $/ \mathbf{s}^{-1}$ \\
\hline$-1.8 \mathrm{~V}$ & 0.0078 \\
\hline$-1.6 \mathrm{~V}$ & 0.0057 \\
\hline$-1.4 \mathrm{~V}$ & 0.0045 \\
\hline$-1.2 \mathrm{~V}$ & 0.0043 \\
\hline$-1.0 \mathrm{~V}$ & 0.0041 \\
\hline
\end{tabular}

The diminution of the constant values as applied potential becomes less negative indicates that there is a progressive decrease in trapped electron reactivity. This is expected as the electrons accumulated as $\mathrm{Ti}^{3+}$ species have different effective electrode potentials (positive to the applied potential). Obviously, only electrons with negative enough potentials can reduce $\mathrm{CO}_{2}$.

On the other hand, under controlled water addition, both methanol and $\mathrm{CO}$ are detected as the main products with Faradaic efficiencies close to $60 \%$ and $17 \%$ respectively. In the presence of water as a proton source, $\mathrm{C}-\mathrm{H}$ coupling is achieved, and the reduction reaction proceeds via proton-electron coupled transfers. ${ }^{60}$ The formation of thermodynamically favored $\mathrm{C}_{1}$ products is feasible. Scheme 2 shows a representation of the $\mathrm{TiO}_{2}$ conduction band position, the onset potential of the Faradaic currents obtained in this study under controlled water addition $(-0.50 \mathrm{~V}$ 
vs SHE) and the potentials versus SHE at $\mathrm{pH} 7$ for some relevant redox couples. Reduction to methanol is thermodynamically feasible although the existence of a relative small overvoltage (understood as the difference in potential between those corresponding to the $\mathrm{CB}$ edge of $\mathrm{TiO}_{2}$ and the $\mathrm{CO}_{2} / \mathrm{CH}_{3} \mathrm{OH}$ redox couple, $\sim 0.12 \mathrm{~V}$ in the present case) could hinder to some extent the process.

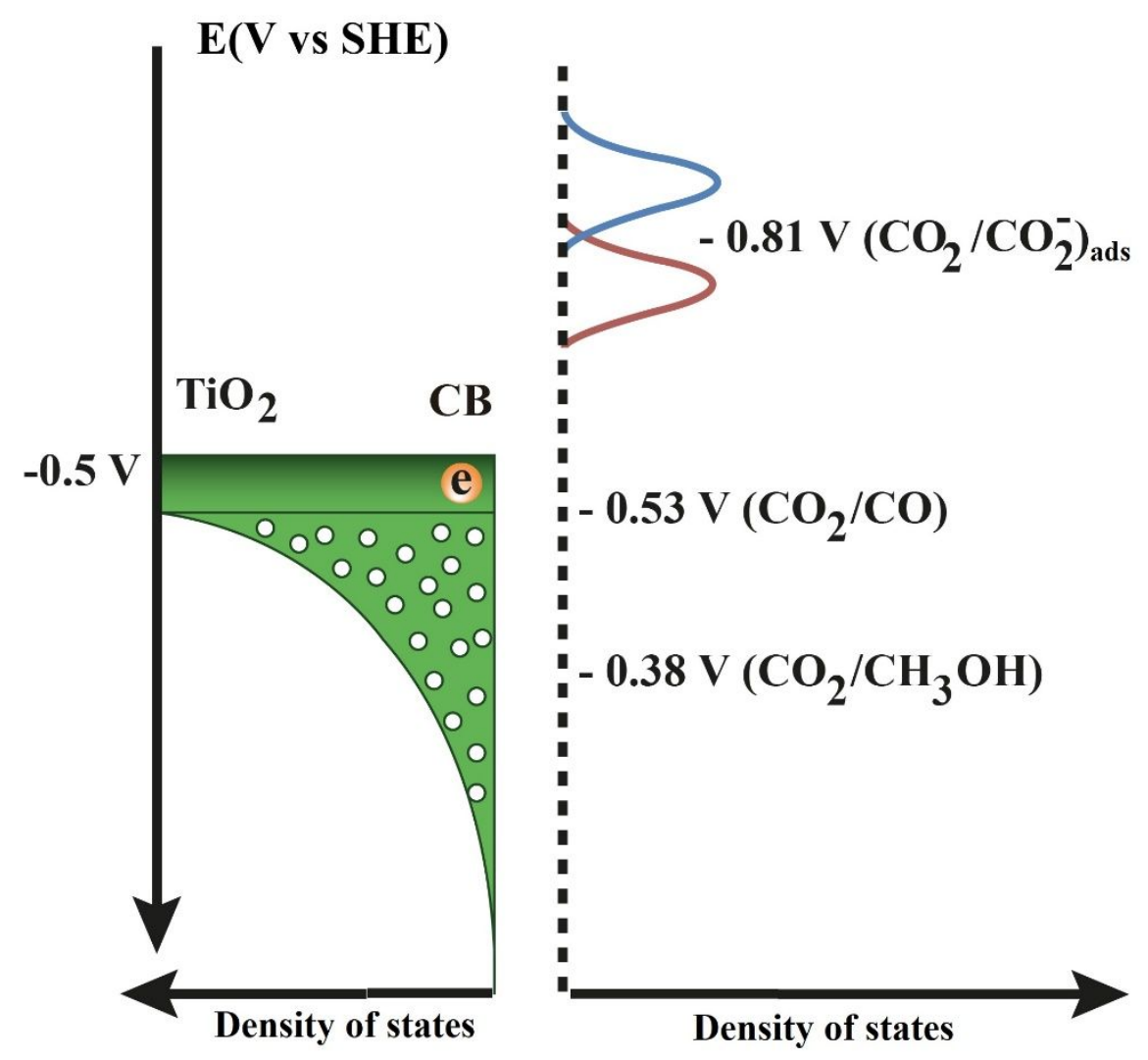

Scheme 2. A sketch showing the conduction band position for $\mathrm{TiO}_{2}$ (vs SHE) and the onset of the Faradaic currents together with the potentials for some relevant redox couples. 


\section{CONCLUSIONS}

The role of oxygen vacancies and $\mathrm{Ti}^{3+}$ species in the $\mathrm{CO}_{2}$ reduction reaction on $\mathrm{TiO}_{2}$ is key for reaching a fundamental understanding of the electrocatalytic activity of $\mathrm{TiO}_{2}$ electrodes. The adsorption of the $\mathrm{CO}_{2}$ molecule on $\mathrm{TiO}_{2}$ not only seems to induce its activation, probably via adduct formation, but it also promotes the oxygen vacancy generation with the subsequent formation of electroreduced $\mathrm{TiO}_{2-y}$ species. This increase in the density of $\mathrm{TiO}_{2-\mathrm{y}}$ species causes the development of capacitive currents, an enhancement in absorbance (electrochromic effect) and a displacement in the IR spectrum baseline at sufficiently negative applied potentials. At open circuit, the decay of $\mathrm{TiO}_{2-\mathrm{y}}$ species, followed by UV/vis spectroelectrochemical measurements, shows that the corresponding rate constant is potential-dependent. Faradaic currents associated with $\mathrm{CO}_{2}$ reduction appear with an onset at $-0.81 \mathrm{~V}$ (vs SHE), being $\mathrm{CO}$ and oxalate the main detected products in dry acetonitrile. The pathway of $\mathrm{CO}$ formation has been related with a model for large-cation containing electrolytes that includes lattice polarization and partial electrodissolution of $\mathrm{TiO}_{2}$. Finally, an enhancement of $\mathrm{CO}_{2}$ reduction has been observed when water is added as witnessed by a significant shift of the onset potential. The analysis of $\mathrm{CO}_{2}$ reduction products shows methanol as the main product in such a case.

The fact that the mechanism proposed initially for $\mathrm{WO}_{3}$ electrodes can be extended to $\mathrm{TiO}_{2}$ electrodes suggests that it could be of general validity for transition metal oxide electrodes. Studies along these lines are underway in our laboratory. 


\section{AUTHOR INFORMATION}

Corresponding Author

*E-mail: roberto.gomez@ua.es. Phone:+34 965903748.

ORCID

Roberto Gomez: 0000-0002-5231-8032

Notes The authors declare no competing financial interest.

Present Addresses

$†$ Department of Chemistry, Universidad de Burgos, Pza. Misael Bañuelos s/n, E-09001 Burgos, Spain

\section{FUNDING SOURCES}

We are grateful for the financial support of the Ministerio de Ciencia, Innovación y Universidades through projects MAT2015-71727-R and RTI2018-102061-B-I00 (FONDOS FEDER).

\section{SUPPORTING INFORMATION}

Additional experimental details. Conversion of measured potentials to the SHE scale. Supplementary figures: additional chronoamperometric and voltammetric curves, additional UVvis spectra and absorbance vs. time curves, and different chromatograms. Supplementary tables: absorbance values and amounts of different species after electrolysis. 


\section{ACKNOWLEDGMENT}

NEMR acknowledges the scholarship COLCIENCIAS National Doctoral Scholarship (567) and Vicerrectorado de Investigación y Transferencia del Conocimiento de la Universidad de Alicante, for the award of a doctoral and travel grants.

\section{REFERENCES}

(1) Centi, G.; Quadrelli, E. A.; Perathoner, S.,"Catalysis for $\mathrm{CO}_{2}$ Conversion: a Key Technology for Rapid Introduction of Renewable Energy in the Value Vhain of Chemical Industries" Energy Environ. Sci. 2013, 6, 1711-1731.

(2) Karl, T. R.; Trenberth, K. E. Modern Global C(1) Karl, T. R.; Trenberth, K. E. Modern Global Climate Change; 2003; Vol. 302.limate Change; 2003; Vol. 302.

(3) Aresta, M.; Dibenedetto, " Utilisation of $\mathrm{CO}_{2}$ as a Chemical Feedstock: Opportunities and Challenges" A. Dalt. Trans. 2007, No. 28, 2975-2992.

(4) K. Fuku, K. Mori, H. Yamashita, in Transformation and Utilization of Carbon Dioxide, Green Chemistry and Sustainable Technology, B.M. Bhanage, M. Arai, eds., Springer, Berlin, 2014. 225. 
(5) Sánchez-Sánchez, C. M.; Montiel, V.; Tryk, D. A.; Aldaz, A.; Fujishima, "Electrochemical Approaches to Alleviation of the Problem of Carbon Dioxide Accumulation" A. Pure Appl. Chem. 2001, 73, 1917-1927.

(6) Habisreutinger, S. N.; Schmidt-Mende, L.; Stolarczyk, J. K. "Photocatalytic Reduction of $\mathrm{CO}_{2}$ on $\mathrm{TiO}_{2}$ and Other Semiconductors" Angew. Chem., Int. Ed. $2013,52,7372-7408$.

(7) Costentin, C.; Robert, M.; Savéant, J.-M.,"Catalysis of the Electrochemical Reduction of Carbon Dioxide", Chem. Soc. Rev. 2013, 42, 2423-2436.

(8) Kang, P.; Chen, Z.; Brookhart, M.; Meyer, T. J., "Electrocatalytic Reduction of Carbon Dioxide: Let the Molecules Do the Work", Top. Catal. 2015, 58, 30-45.

(9) Hori, Y.; Kikuchi, K.; Suzuki, S., "Production of $\mathrm{CO}$ and $\mathrm{CH}_{4}$ in Electrochemical Reduction of $\mathrm{CO}_{2}$ at Metal Electrodes in Aqueous Hydrogencarbonate Solutions", Chem. Lett. 1985, 14, 1695-1698.

(10) Berto, T. C.; Zhang, L.; Hamers, R. J.; Berry, J. F., "Electrolyte Dependence of 
$\mathrm{CO}_{2}$ Electroreduction: Tetraalkylammonium lons Are Not Electrocatalysts", ACS

Catal. 2015, 5, 703-707.

(11) Ganesh, I., "Conversion of Carbon Dioxide into Methanol - a Potential Liquid Fuel: Fundamental Challenges and Opportunities (a Review)", Renew. Sustain. Energy Rev. 2014, 31, 221-257.

(12) Méndez, M. A.; Voyame, P.; Girault, H. H., "Interfacial Photoreduction of Supercritical $\mathrm{CO}_{2}$ by an Aqueous Catalyst", Angew. Chem. Int. Ed. Engl. 2011, $50,7391-7394$.

(13) Freund, H.-J.; Roberts, M. W., "Surface Chemistry of Carbon Dioxide", Surf. Sci. Rep. 1996, 25, 225-273.

(14) Busca, G.; Lorenzelli, V., "Infrared Spectroscopic Identification of Species Arising from Reactive Adsorption of Carbon Oxides on Metal Oxide Surfaces", Mater. Chem. 1982, 7, 89-126.

(15) Fukuda, Y.; Toyoshima, I., "AES And UPS Studies Of $\mathrm{CO}$ And $\mathrm{CO}_{2}$ Adsorption On 
Mg And Mgo", Surf. Sci. 1985, 158, 482-489.

(16) Pan, Y.; Liu, C.; Wiltowski, T. S.; Ge, Q., "CO $\mathrm{CO}_{2}$ Adsorption and Activation Over Y$\mathrm{Al}_{2} \mathrm{O}_{3}$-Supported Transition Metal Dimers: A Density Functional Study", Catal. Today 2009, 147, 68-76.

(17) Rasko, J.; Solymosi, F., "Infrared Spectroscopic Study of the Photoinduced Activation of $\mathrm{CO}_{2}$ on $\mathrm{TiO}_{2}$ and $\mathrm{Rh} / \mathrm{TiO}_{2}$ Catalysts", J. Phys. Chem. 1994, 98, 7147-7152.

(18) Tomita, Y.; Hori, Y. In Advances in Chemical Conversions for Mitigating Carbon DioxideProceedings of the Fourth International Conference on Carbon Dioxide Utilization; T. Inui K. Izui, S. Yanagida and T. Yamaguchi - Studies in Surface Science and Catalysis, M. A., Ed.; Elsevier, 1998; Vol.114, pp 581-584.

(19) Rudnev, A. V.; Zhumaev, U. E.; Kuzume, A.; Vesztergom, S.; Furrer, J.; Broekmann, P.; Wandlowski, T., "The Promoting Effect of Water on the Electroreduction of $\mathrm{CO}_{2}$ in Acetonitrile", Electrochim. Acta 2016, 189, 38-44. 
(20) Amatore, C.; Saveant, J. M., "Mechanism and Kinetic Characteristics of the Electrochemical Reduction of Carbon Dioxide in Media of Low Proton Availability", J. Am. Chem. Soc. 1981, 103, 5021-5023.

(21) Gennaro, A.; Isse, A. A.; Severin, M.-G.; Vianello, E.; Bhugun, I.; Saveant, J.-M., "Mechanism of the Electrochemical Reduction of Carbon Dioxide at Inert Electrodes in Media of Low Proton Availability", J. Chem. Soc. Faraday Trans. 1996, 92, 3963-3968.

(22) Baruch, M. F.; Pander, J.; White, J. L.; Bocarsly, A. B., "Mechanistic Insights into the Reduction of $\mathrm{CO}_{2}$ on Tin Electrodes Using In Situ ATR-IR Spectroscopy", ACS Catal. 2015, 5, 3148.

(23) Ayemoba, O.; Cuesta, A., "Spectroscopic Evidence of Size-Dependent Buffering of Interfacial pH by Cation Hydrolysis during $\mathrm{CO}_{2}$ Electroreduction", ACS Appl. Mater. Interfaces 2017, 9, 27377-27382.

(24) Dunwell, M.; Yang, X.; Setzler, B. P.; Anibal, J.; Yan, Y.; Xu, B., "Examination of Near-Electrode Concentration Gradients and Kinetic Impacts on the 
Electrochemical Reduction of $\mathrm{CO}_{2}$ using Surface-Enhanced Infrared Spectroscopy", ACS Catal. 2018, 8(5), 3999-4008.

(25) Desilvestro, J.; Pons, S., "The Cathodic Reduction of Carbon Dioxide in Acetonitrile: An Electrochemical and Infrared Spectroelectrochemical Study", J. Electroanal. Chem. Interfacial Electrochem. 1989, 267, 207-220.

(26) Christensen, P. A.; Hamnett, A.; Muir, A. V. G.; Freeman, N. A., " $\mathrm{CO}_{2}$ Reduction at Platinum, Gold And Glassy Carbon Electrodes In Acetonitrile: An In-Situ FTIR Study", J. Electroanal. Chem. Interfacial Electrochem. 1990, 288, 197-215.

(27) Figueiredo, M. C.; Ledezma-Yanez, I.; Koper, M. T. M., " In Situ Spectroscopic Study of $\mathrm{CO}_{2}$ Electroreduction at Copper Electrodes in Acetonitrile", ACS Catal. 2016, 6, 2382-2392.

(28) Tomita, Y.; Teruya, S.; Koga, O.; Hori, Y., " Electrochemical Reduction of Carbon Dioxide at a Platinum Electrode in Acetonitrile-Water Mixtures", Electrochem. Soc. 2000, 147, 4164-4167. 
(29) Ito, K.; Ikeda, ; Yamauchi, N.; lida, T.; Takagi T., "Electrochemical Reduction

Products of Carbon Dioxide at Some Metallic Electrodes in Nonaqueous

Electrolytes ", Bull. Chem. Soc. Jpn. 1985, 58, 3027-3028

(30) Yang, C..; Yu, Y.; van der Linden, B.; Wu, J. C. S.; Mul, G., "Artificial Photosynthesis over Crystalline $\mathrm{TiO}_{2}$-Based Catalysts: Fact or Fiction?", J. Am.

Chem. Soc. 2010, 132, 8398-8406.

(31) Mendieta-Reyes, N. E.; Díaz-García, A. K.; Gómez, R., "Simultaneous Electrocatalytic $\mathrm{CO}_{2}$ Reduction and Enhanced Electrochromic Effect at $\mathrm{WO}_{3}$ Nanostructured Electrodes in Acetonitrile", ACS Catal. 2018, 1903-1912.

(32) Hepel, M.; Redmond, H., "Large Cation Model of Dissociative Reduction of Electrochromic $\mathrm{WO}_{3}$ Films", Cent. Eur. J. Chem. 2009, 7, 234-245.

(33) Jankulovska, M.; Berger, T.; Wong, S. S.; Gómez, R.; Lana-Villarreal, T., " Trap States in $\mathrm{TiO}_{2}$ Films Made of Nanowires, Nanotubes or Nanoparticles: An Electrochemical Study", ChemPhysChem 2012, 13, 3008-3017. 
(34) Williams, D. B. G.; Lawton, M., "Drying of Organic Solvents: Quantitative Evaluation of the Efficiency of Several Desiccants", J. Org. Chem. 2010, 75, 8351-8354.

(35) Kannan, R.; Kakade, B. A.; Pillai, V. K., "Polymer Electrolyte Fuel Cells Using Nafion-Based Composite Membranes with Functionalized Carbon Nanotubes", Angew. Chem. Int. Ed. Engl. 2008, 47, 2653-2656.

(36) Lana-Villarreal, T.; Mao, Y.; Wong, S. S.; Gomez, R., "Photoelectrochemical Behaviour of Anatase Nanoporous Films: Effect of the Nanoparticle Organization", Nanoscale 2010, 2, 1690-1698.

(37) Berger, T.; Lana-Villarreal, T.; Monllor-Satoca, D.; Gómez, R., " An Electrochemical Study on the Nature of Trap States in Nanocrystalline Rutile Thin Films", J. Phys. Chem. C 2007, 111, 9936-9942.

(38) Hepel, M.; Wickham, D., "Large Cation Model of Dissociative Reduction of $\mathrm{WO}_{3}$ Lattice Studied by EQCN and AFM", In ECS Transactions, 2009,19, 11-23. 
(39) Pavlishchuk, V. V; Addison, A.W., "Conversion Constants for Redox Potentials Measured Versus Different Reference Electrodes in Acetonitrile Solutions at $25^{\circ} \mathrm{C}$, Inorganica Chim. Acta 2000, 298, 97-102.

(40) Bockris, J. O.; Wass, J. C., "On the Photoelectrocatalytic Reduction of Carbon Dioxide" Mater. Chem. Phys. 1989, 22, 249-280.

(41) Saeki, T.; Hashimoto, K.; Kimura, N.; Omata, K.; Fujishima, A., "Electrochemical Reduction of $\mathrm{CO}_{2}$ with High Current Density in a $\mathrm{CO}_{2}+$ Methanol Medium II. CO Formation Promoted by Tetrabutylammonium Cation", J. Electroanal. Chem. 1995, 390, 77-82.

(42) Ramesha, G. K.; Brennecke, J. F.; Kamat, P. V., "Origin of Catalytic Effect in the Reduction of $\mathrm{CO}_{2}$ at Nanostructured $\mathrm{TiO}_{2}$ Films", ACS Catal. 2014, 4, 32493254.

(43) Davit, P.; Martra, G.; Coluccia, S.; Augugliaro, V.; García López, E.; Loddo, V.; Marcì, G.; Palmisano, L.; Schiavello, M., "Adsorption and Photocatalytic Degradation of Acetonitrile: FT-IR Investigation" J. Mol. Catal. A Chem. 2003, 
693-701.

(44) Zhuang, J.; Rusu, C. N.; Yates, J. T., "Adsorption and Photooxidation of $\mathrm{CH}_{3} \mathrm{CN}$ on $\mathrm{TiO}_{2} "$ J. Phys. Chem. B 1999, 103, 6957-6967.

(45) Hubbard, A. T.; Cao, E. Y.; Stern, D. A., "Surface Analysis of Electrodes by UltraHigh Vacuum Techniques: Acetonitrile Solvent Chemisorption at Pt(111)", Electrochim. Acta 1994, 39, 1007-1014.

(46) Morterra, C.; Peñarroya Mentruit, M.; Cerrato, G., "Acetonitrile Adsorption as an IR spectroscopic Probe for Surface Acidity/Basicity of Pure and Modified Zirconias", Phys. Chem. Chem. Phys. 2002, 4, 676-687.

(47) Chuang, C.-C.; Wu, W.-C.; Lee, M.-X.; Lin, J.-L., "Adsorption and Photochemistry of $\mathrm{CH}_{3} \mathrm{CN}$ and $\mathrm{CH}_{3} \mathrm{CONH}_{2}$ on Powdered $\mathrm{TiO}_{2}$ ", Phys. Chem. Chem. Phys. 2000, 2, 3877-3882.

(48) Foley, J. K.; Korzeniewski, C.; Pons, S., "Anodic and Cathodic Reactions in Acetonitrile/Tetra-N-Butylammonium Tetrafluoroborate: An Electrochemical And 
Infrared Spectroelectrochemical Study", Can. J. Chem. 1988, 66, 201-206.

(49) Berger, T.; Anta, J. A.; Morales-Florez, V., "Spectroscopic Properties of Electrochemically Populated Electronic States in Nanostructured $\mathrm{TiO}_{2}$ Films: Anatase versus Rutile", Phys. Chem. Chem. Phys. 2013, 15, 13790-13795.

(50) Hadjiivanov, K.; Lamotte, J.; Lavalley, J.-C., "FTIR Study of Low-Temperature CO Adsorption on Pure and Ammonia-Precovered $\mathrm{TiO}_{2}$ (Anatase)", Langmuir 1997, $13(13), 3374-3381$.

(51) Liao, L.-F.; Lien, C.-F.; Shieh, D.-L.; Chen, M.-T.; Lin, J.-L., "FTIR Study of Adsorption and Photoassisted Oxygen Isotopic Exchange of Carbon Monoxide, Carbon Dioxide, Carbonate, and Formate on $\mathrm{TiO}_{2}$ ", J. Phys. Chem. B 2002, 106 (43), $11240-11245$.

(52) Lustemberg, P. G.; Scherlis, D. A., "Monoxide carbon frequency shift as a tool for the characterization of $\mathrm{TiO}_{2}$ surfaces: Insights from first principles spectroscopy", J. Chem. Phys. 2013, 138 (12), 124702. 
(53) Lamy, E.; Nadjo, L.; Savéant, J. M., "Standard Potential and Kinetic Parameters of the Electrochemical Reduction of Carbon Dioxide in Dimethylformamide", $\mathrm{J}$. Electroanal. Chem. Interfacial Electrochem. 1977, 78, 403.

(54) Indrakanti, V. P.; Kubicki, J. D.; Schobert, H. H., "Photoinduced Activation of $\mathrm{CO}_{2}$ on Ti-Based Heterogeneous Catalysts: Current State, Chemical Physics-Based Insights and Outlook", Energy Environ. Sci. 2009, 2, 745-758.

(55) Dan C., S.; Junseok, L.; Wissam A., A.-S.; Kenneth D., " $\mathrm{CO}_{2}$ Adsorption on $\mathrm{TiO}_{2}(110)$ Rutile: Insight from Dispersion-Corrected Density Functional Theory Calculations and Scanning Tunneling Microscopy Experiments", J. Chem. Phys. 2011, 134, 104707.

(56) Xiong, L. Bin; Li, J. L.; Yang, B.; Yu, Y., "Ti ${ }^{3+}$ in the Surface of Titanium Dioxide: Generation, Properties and Photocatalytic Application", J. Nanomater. 2012, 2012. ID 831524,13 pages

(57) Liu, L.; Jiang, Y.; Zhao, H.; Chen, J.; Cheng, J.; Yang, K.; Li, Y., "Engineering Coexposed $\{001\}$ and $\{101\}$ Facets in Oxygen-Deficient $\mathrm{TiO}_{2}$ Nanocrystals for 
Enhanced CO2 Photoreduction under Visible Light", ACS Catal. 2016, 6, 10971108.

(58) Chauvaut, V.; Duval, E.; Malinowska, B.; Cassir, M.; Marcus, P., "XPS Study of Titanium Species Exposed to Molten $\mathrm{Li}_{2} \mathrm{CO}_{3}-\mathrm{Na}_{2} \mathrm{CO}_{3}$ in the Anodic Conditions Used in Molten Carbonate Fuel Cells", J. Mater. Sci. 1999, 34, 2015-2022.

(59) Lee, J.; Sorescu, D. C.; Deng, X., "Electron-Induced Dissociation of $\mathrm{CO}_{2}$ on $\mathrm{TiO}_{2}(110) "$, J. Am. Chem. Soc. 2011, 133, 10066-10069.

(60) Matsubara, Y.; Grills, D. C.; Kuwahara, Y., "Thermodynamic Aspects of Electrocatalytic $\mathrm{CO}_{2}$ Reduction in Acetonitrile and with an Ionic Liquid as Solvent or Electrolyte", ACS Catal. 2015, 5, 6440-6452. 